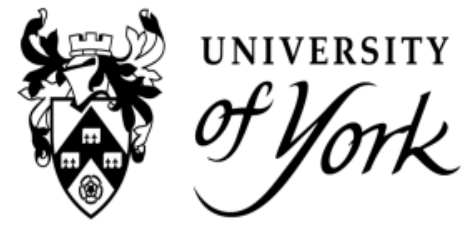

\section{HEDG}

WP $17 / 09$

\section{The Externalities of a Deforestation Control Policy in Infant Health: Evidence from Brazil}

Bladimir Carrillo; Danyelle Branco; Juan Trujillo and João Lima

\author{
March 2017
}




\title{
The Externalities of a Deforestation Control Policy in Infant Health: Evidence from Brazil $^{*}$
}

\author{
Bladimir Carrillo \\ Danyelle Branco \\ Juan Trujillo \\ João Lima
}

November 2016

\begin{abstract}
The burning of forest releases a wide range of contaminants, some of which are known to be hazardous for health. Traditional estimates of the costs of deforestation rarely incorporate the health effects of pollution generated by deforestation. This paper provides the first estimates of the local externalities of deforestation in infant health. Our approach exploits a conservation policy that generated a sharp drop in deforestation across municipalities in the Brazilian Amazon. The core findings are that deforestation control policy led to reductions in the incidence of very low birth weight and extreme prematurity, especially for boys. Collectively, these findings provide additional justification for controlling deforestation.
\end{abstract}

Keywords: Deforestation; Environmental Quality; Conservation Policy; Infant Health; Brazil JEL Classification: I12, K32, Q51

\footnotetext{
* We thank the editor Marcel Fafchamps and three anonymous referees for useful comments and suggestions. We also benefit from the suggestions of Siân de Bell, Sarah Knight, Eric Marr, Gustavo Feres, Terciani Sabadini, Marcelo Ferreira, and seminar participants at the 2015 Meeting of the International Conference of Agricultural Economist, and the 2014 Meeting of the Brazilian Association of Graduate Programs in Economics. This study was supported by the Coordenação de Aperfeiçoamento de Pessoal de Nivel Superior (CAPES), Brazil. Dumar Vargas, and Elkyn Navas provided excellent research assistance. Bladimir Carrillo: Department of Rural Economics, Universidade Federal de Viçosa, email: bladimir.bermudez@ufv.br. Danyelle Branco: Department of Rural Economics, Universidade Federal de Viçosa, email: danyelle.branco@ufv.br. Juan Trujillo: Department of Environment, University of York, email: juan.trujillo@york.ac.uk. João Lima: Department of Rural Economics, Universidade Federal de Viçosa, email:jelima@ufv.br.
} 


\section{Introduction}

The externalities of deforestation are an increasingly salient issue in the debate about the costs and benefits of conservation policies. ${ }^{1}$ The smoke from the burning of forest contains a wide range of contaminants, including fine particulate pollution $\left(\mathrm{PM}_{10}\right)$, sulfur oxide $\left(\mathrm{SO}_{2}\right)$ and carbon monoxide (CO), some of which are known to be hazardous for health. ${ }^{2}$ At the same time, penetration of sunlight and water accumulation in cleared forests brought by deforestation in rural areas may favor proliferation of malaria-carrying parasites (Vittor et al. 2006; Vittor et al. 2009; Olson et al. 2010). Many previous studies show that exposure during pregnancy to malaria and air pollution is associated with increased risk of poor birth outcomes (Currie, Neidell, and Schmieder 2009; Glinianaia et al. 2004; Guyatt and Snow 2004). Despite this, traditional estimates of the costs of deforestation rarely address local externalities such as the health effects of deforestation.

Learning about the consequences of deforestation for infant health may be particularly compelling to policy makers. Previous studies have documented that poor fetal conditions have adverse effects on later life outcomes. For instance, in utero exposure to air pollution or malaria is associated with reduced cognitive abilities, lower educational attainment and lower income (Isen, Rossin-Slater, and Walker 2014; Sanders 2012; Venkataramani 2012; Barreca 2010; Almond, Edlund, and Palme 2009). Therefore, evidence that deforestation impairs fetal health may influence policy debates over the costs and benefits of deforestation control.

This paper provides estimates of the effects of deforestation on infant health by examining a conservation policy that generated a sharp drop in deforestation within the Brazilian Amazon. Assunção, Gandour, and Rocha (2015) show that the Action Plan for the Prevention and Control of Deforestation in the Legal Amazon (PPCDAM) substantially reduced deforestation across municipalities. We investigate the effect of PPCDAM, and thus the sharp reductions in deforestation, on infant health. The Brazilian Amazon is an excellent place to study these questions because it is large (its forest of around 5 million $\mathrm{km} 2$ is

\footnotetext{
${ }^{1}$ In this study, deforestation is defined as the conversion of forested land to non-forested land.

2 The effects of deforestation on air pollution might be particularly more pronounced if deforestation is done for agricultural purposes. One example is deforestation for sugarcane production purposes, which requires burning to remove plant debris, weeds and pests.
} 
equivalent to half the total area of Europe) and has detailed information on deforestation and infant health before and after intervention, providing an opportunity to answer these questions with extensive panel data.

The PPCDAM, launched in 2004, introduced new procedures to combat deforestation in the Amazon. In particular, it introduced the use of new satellites to detect and locate deforestation activities in real time. Once detected and localized, environmental police soon arrive to the area being deforested and conduct sanctions which include arrests, fines, seizure, confiscation and destruction of production materials. These satellites allowed closer monitoring of deforestation activities. The PPCDAM also promoted the creation of conservation units, leading to an unprecedented increase in the number of conservation areas in Amazon. A rapid and sharp reduction in deforestation characterized the post-intervention years, with deforestation declining from 27,000 $\mathrm{km}^{2}$ in 2004 to $12,000 \mathrm{~km}^{2}$ in 2008.

In the absence of a randomized trial, our research design uses the large reductions in deforestation across municipalities generated by the PPCDAM. Specifically, our identification strategy exploits the fact that areas with higher pre-intervention deforestation were more likely to benefit from the conservation policy in terms of absolute reductions in deforestation. Our analysis then compares changes in birth outcomes before and after intervention in municipalities with different levels of pre-intervention deforestation. We define the timeframe of 2005-2008 as the post-intervention period and 1998-2004 as the pre-intervention period. Our core findings are that deforestation control policy led to lower incidence of very low birth weight and extreme prematurity. We also estimate the effects separately for boys and girls. Understanding whether there are gender differences is importantly in view that previous studies have found that male fetuses are more vulnerable to in utero shocks than female fetuses (Almond and Mazumder 2011; Eriksson et al. 2010; Kraemer 2000). Consistent with this literature, we find that the effects of the deforestation control policy were larger in magnitude for boys.

To gain insight into the effects of deforestation control policy on infant health, we tested whether PPCDAM had significant effects on air pollution. The data indicate that conservation policy led to reductions in the levels of $\mathrm{PM}_{10}, \mathrm{CO}$, and $\mathrm{SO}_{2}$. These findings 
suggest that improvements in air pollution were a plausible mechanism through which the PPCDAM led to better birth outcomes. However, we are unable to rule out the possibility that other non-environmental channels, such as changes in socioeconomic outcomes, play a role. Thus, our results should be interpreted as the reduced form effect of prenatal exposure to the deforestation control policy. Collectively, our findings suggest that deforestation control policies have positive externalities on infant health.

At this point, we should emphasize that there are various issues that may affect the validity of our findings. As in previous works in the birth outcome literature, we cannot fully address the issue of fetus selection. ${ }^{3}$ The problem is that we only observe birth outcomes for surviving (and presumably stronger) fetuses. The use of this select sample most likely will bias our estimates of the effect of PPCDAM towards zero, so our effects can be taken to be lower bounds. To investigate this potential bias, we estimate the effect of PPCDAM on fetal deaths. We show that policy had, at best, small effects on fetal deaths. The shortcoming of this exercise is that fetal death records are likely to be subject to measurement error. So, we also investigate whether control policy affected sex ratios. If fetus selection is an important issue, then we should see significant increases in sex ratios in favor of the boys, as predicted by literature on "fragile males". We find no significant effects on sex ratios, providing further evidence that bias associated with fetus selection in our sample is small.

More importantly, our estimates could be confounded with those of the Bolsa Familia (BF) program, a national antipoverty intervention that was also launched in 2004. We account for this possibility by directly including as a control in all specifications the interaction between a post-intervention dummy and the average percentage of beneficiary families. Since the BF program focused on the poorest municipalities, we also include as additional controls the interactions between a post-intervention dummy and 2004 GDP, child labor rate, illiteracy rate, and sanitation coverage. Reassuringly, our estimates are insensitive to using these controls.

Our research design relies on the assumption that the characteristics of mothers in municipalities with higher pre-intervention deforestation change over time in a way that is

\footnotetext{
${ }^{3}$ See, for example, Currie (2009).
} 
comparable to those of other mothers who live in municipalities with less pre-intervention deforestation. We test this assumption by examining whether observable characteristics of mothers change differentially before and after conservation policy adoption. We find that PPCDAM is not associated with changes in maternal characteristics, suggesting that the composition of women giving birth shows little change in the immediate aftermath of policy adoption.

Our paper relates to a set of studies that tried to estimate the effects of deforestation on health outcomes. Sastry (2002) showed that forest burning is associated with increased risk of mortality in Malaysia. Frankenberg, McKee, and Thomas (2005) found that forest burning is associated with worse self-reported health status in Indonesia. Recently, Garg (2014) found that deforestation is associated with increases in the likelihood of malaria infection in Indonesia. The major difference between these studies and ours is that they focused on adult population. In contrast, our study is the first attempt to show the systematic importance of controlling deforestation for infant health. The study of newborns overcomes several methodological difficulties. In particular, the focus on infants mitigates the problem of unknown lifetime exposure by the low migration rates of pregnant women.

The remainder of this paper is structured as follows. The following section presents a description of the PPCDAM and a review of the channels through which policy conservation may affect infant health. Section 3 describes our data set. Section 4 outlines our basic research strategy. Section 5 presents our main results. Finally, Section 6 presents our conclusions.

\section{Background}

\subsection{Conservation Policy Efforts in Brazil}

Prior to the commencement of policy conservation in 2004, deforestation was rapidly increasing in the Brazilian Amazon, with deforestation estimated at nearly 22,000 kilometers squared annually (2001-2004 years). Roughly 90\% of deforestation was concentrated in four

out of the nine Legal Amazon states: Amazonas, Mato Grosso, Pará and Rondônia. As a result, these states were a priority in efforts to control deforestation. 
In 2004, the Brazilian federal government and the Ministry of the Environment launched the PPCDAM, which presented a set of strategies to combat deforestation in Brazilian Amazon as part of a mutual effort between federal, state and municipal governments. These strategies were implemented in coordination with specialized agencies such as the Brazilian Army, the Federal Police, and the National Institute for Space Research (INPE). This facilitated the implementation of innovative processes focused on command and control, territorial management and land use, and promotion of sustainable practices. By 2020, PPCDAM seeks to reduce deforestation $80 \%$ from the estimated 27,000 km² in 2004.

One of the most important strategies of the PPCDAM was the introduction of the RealTime System for Detection of Deforestation (DETER), a satellite-based system that records geo-referenced images on forest cover. Managed by INPE, this system was introduced to closely monitor deforestation activities. From images generated at intervals of 15 days, areas being deforested are detected. Once deforestation activities are identified, INPE issues alert signals to the police responsible for enforcing environmental laws in Brazilian Amazon. Police arrive to the area being deforested and apply sanctions to infringers. Such sanctions include arrests, fines, seizures, confiscation and destruction of goods, tools, and production materials. Before the adoption of DETER, monitoring activities were based on voluntary reports, which limited law enforcement.

The PPCDAM also promoted the creation of conservation units of integral protection in the Brazilian Amazon. As a result, the conservation areas increased by about 500,000 $\mathrm{km}^{2}$ from 2004 through 2008. In 2009, nearly $40 \%$ of the territory in the Amazon was classified as protected. To control deforestation, the creation of conservation units focused on the municipalities that had recorded higher deforestation in the pre-intervention period.

Finally, the PPCDAM used two strategies to promote sustainable practices. First, the policy promoted large-scale training in forest management techniques and organic farming. Second, through credits and tax exemptions, the policy supported projects focused on organic farming, ecological agriculture, and recovery of degraded areas. Anyone with a sustainable project in the Amazon was eligible for funding. This strategy could be interpreted as a mechanism to compensate communities who adopt lower deforestation. 
By all accounts, the deforestation control efforts were extremely successful in the short and medium terms. For example, in 2008, deforestation per year in Amazon fell to 12,000 $\mathrm{km}^{2}$. The bulk of these declines occurred in areas with the higher deforestation prior to the intervention. Indeed, Assunção, Gandour, and Rocha (2015) illustrate a strong crossmunicipality convergence in the annual deforested area (in $\mathrm{km}^{2}$ ) after 2004. While deforestation was not completely controlled, deforestation levels declined and remained low throughout the 2000 s relative to the pre-intervention era.

\subsection{Conservation Policy and Infant Health}

We draw from existing literature insights to identify the main mechanisms underlying the effects of PPCDAM on infant health. There are at least three ways, or channels, through which policy conservation may have affected infant health. We describe these channels below.

\subsubsection{Air Pollution}

Smoke from forest burning contains contaminants hazardous to health, including $\mathrm{PM}_{10}, \mathrm{SO}_{2}$ and CO (Yokelson et al. 2007). ${ }^{4}$ The contaminants believed to be more harmful to health are $\mathrm{PM}_{10}$ and $\mathrm{CO} . \mathrm{PM}_{10}$ is thought to be harmful because it concentrates in the blood and weakens the immune system (Seaton et al. 1995). Although $\mathrm{PM}_{10}$ cannot cross the placenta, it may affect fetal health indirectly through deterioration in maternal health. On the other hand, $\mathrm{CO}$ directly reduces the availability of oxygen to the fetus. In addition, $\mathrm{CO}$ can easily cross the placenta and reach high levels of concentration in its blood. Previous studies show that exposure to $\mathrm{PM}_{10}$ and $\mathrm{CO}$ is associated with increased risk of low birth weight and prematurity, even at relatively low levels of pollution (Currie, Neidell, and Schmieder 2009; Currie and Walker 2011; Currie and Neidell 2005). ${ }^{5}$ Previous studies also have found that $\mathrm{SO}_{2}$ is associated with worse birth outcomes (Arceo, Hanna, and Oliva 2015). Taken together, these

\footnotetext{
${ }^{4}$ One major cause of forest burning is human activity. Most human-induced forest burning clears land for agricultural or settlement purposes. Given its low cost and efficiency, it is not surprising that forest burning is a common practice. For the Brazilian Amazon, some estimates suggest that, on average, the fire-damaged area represents up to 55\% of the annual area deforested (Morton et al. 2011).

${ }^{5}$ For a complete review of the literature in general, see Glinianaia et al. 2004.
} 
facts suggest that the PPCDAM may have positive externalities on infant health through reductions in air pollution.

\subsubsection{Malaria Risk}

Lower malaria risk is also a potential mechanism through which the PPCDAM could contribute to better fetal health. Deforestation in rural areas may favor specific mosquitoes capable of carrying malaria. The development of such mosquitoes depends on sunlight and humidity. Cleared forests receive more sunlight and are more susceptible to the formation of puddles with a neutral pH, favoring the development of these mosquitoes (Vittor et al. 2006; Vittor et al. 2009; Olson et al. 2010). There is evidence supporting this. For example, Vittor et al. (2006) found that the risk of being bitten by the primary vector of malaria in the Amazon, Anopheles darlingi, is 278 times higher in deforested areas than in those that were predominantly forested in Peru. However, not all mosquitoes carry parasites, and thus not all bites result in malaria. Therefore, this evidence is only suggestive of a link between deforestation and malaria. For the Brazilian Amazon, Hahn et al. (2014) also found evidence suggesting that higher deforestation leads to increased risk of malaria.

Malaria affects fetal health through direct transmission from the mother (Menendez and Mayor 2007; Poespoprodjo et al. 2010). In addition, the diversion of energy from the mother to fight against the disease can harm the fetus, restricting food intake and causing oxygen deprivation associated with anemia (Crimmins and Finch 2006). There is evidence showing that malaria in utero is associated with poorer birth outcomes (Guyatt and Snow 2004; Sarr et al. 2006; Huynh et al. 2011). In addition, there is indirect evidence documenting that exposure to malaria during pregnancy has negative effects on fetal health. For example, Chang et al. (2014) show that individuals exposed to malaria during pregnancy have higher risk of cardiovascular diseases. ${ }^{6}$

\footnotetext{
${ }^{6}$ In absolute terms, around 4 million people in the Brazilian Amazon region are at high risk of malaria, a figure that is similar to that of Sierra Leone, the country with the highest rate of deaths from malaria. In relative terms, around 800 cases per hundred thousand inhabitants per year are reported in the Brazilian Amazon; this is 34 times lower than that of Sierra Leone. While the risk of malaria in Brazil is not substantially high, we do not rule out the possibility that it plays a role.
} 


\subsubsection{Agricultural Productivity and Income}

As we mentioned before, PPCDAM offered credits for sustainable projects. At least in the short term, this could have resulted in higher income. In turn, higher income means more consumption and better nutrition during pregnancy. There is consistent evidence showing that improved nutrition during pregnancy leads to better birth outcomes, including reduced risk of low birth weight and prematurity (Almond and Mazumder 2011). Through the income channel, then, conservation policy could have positive externalities on infant health.

Alternatively, if conservation policy was effective in controlling deforestation, then it could have adversely affected agricultural activities. For example, the production of sugarcane requires the use of large tracks of land around processing plants, which generates pressure on deforestation. Thus, a possibility is that the new conservation policy could have reduced production of such agricultural activities due to lower productivity and thereby led to a reduction in household income. Through this channel, the PPCDAM could contribute to higher risk of poor birth outcomes.

Overall, the net effect of deforestation policy on income is ambiguous. Indeed, previous studies have failed to show that conservation policy is associated with significant changes in local economic variables such as GDP (Assunção, Gandour, and Rocha 2015; Ferreira, Ribera, and Horridge 2015). Since both effects work in opposite directions, one possibility is that they happen to cancel each other out so that the reduced form estimates of the effects of policy on income are zero. We also present evidence consistent with previous studies that the PPCDAM had, at best, small effects on income.

\section{Data}

Our analysis is based on a municipality-by-year unbalanced panel data for the 1998-2008 period. ${ }^{7}$ The analysis use all municipalities of Amazon states considered priorities, which comprise about $90 \%$ of the total deforestation. We do not include subsequent years to 2008 in the analysis as an effort to compare infants born immediately after the policy adoption with those born before. In total, there are 396 municipalities in the sample. These municipalities account for approximately $62 \%$ of total population in the Brazilian Amazon.

\footnotetext{
7 The panel is unbalanced due to the presence of missing values in some variables. However, the incidence of missing is relatively small (about $1 \%$ of all observations).
} 


\subsection{Birth Outcomes}

Our microdata for birth outcomes come from the Brazilian National System of Information on Birth Records, which records all births in Brazil. Its data do not, however, cover most municipalities in our sample before 1998. For this reason, our period of analysis is 1998-2008 - approximately 3 million birth records. ${ }^{8}$ The data includes the exact date of birth, weeks of gestation, sex, birth weight, and maternal characteristics such as marital status, age and education. The database also provides the municipality of residence of the mother. Based on this information, we construct a municipality-by-year of birth panel over the 1998-2008 period. Since we use the municipality in which the mother lives as a reference for the panel, we are able to capture exposure in utero to changes in deforestation.

The consolidated dataset allows us to calculate rates of low birth weight (defined as birth weight less than 2,500 grams), very low birth weight (defined as birth weight less than 1,500 grams), prematurity (defined as gestation less than 38 weeks), and extreme prematurity (defined as gestation less than 28 weeks) by municipality and year of birth. In the original dataset, the length of pregnancy is coded into categories. From 2000 onwards, this variable was collected using different categories, making it impossible to compare with previous years. Therefore, our analysis for prematurity corresponds to the period 2000-2008. We also build these variables separately for girls and boys.

Using this dataset, we also calculate three additional variables: $i$ ) rates of births from mothers with over 12 years of education ${ }^{9}$; ii) fraction of newborns from teenage mother (age $<20$ years); and iii) rates of births from married mothers (available from 2000). ${ }^{10}$ Table 1 presents a statistical summary of all variables. On average, there are 715 births per municipality per year. 5.8\% of these infants have low birth weight. Premature birth rate is $6.1 \%$. Rates of births from teenage and married mothers are 31 and $30 \%$, respectively.

\footnotetext{
${ }^{8}$ This includes infants from mothers residing in rural and urban areas. Since data do not provide the type of municipal area, we are not able to identify births from mothers residing in rural areas.

${ }^{9}$ We use 12 years of education as cut-off in Brazil because that is the number of school years required for a high school degree.

${ }^{10}$ Since the rates of newborns from married mothers are available from 2000, we do not include this variable in the birth weight regressions for more precise estimates. However, the inclusion of this variable does not alter our results.
} 


\subsection{Deforestation}

Deforestation data are collected by INPE, which has used municipality-level satellite imagery since 2000. We define deforestation as $\mathrm{km}^{2}$ of forest cleared annually (i.e., the increment in the total area deforested between years $t$ and $t$-1). We used annual forest cleared in $\mathrm{km}^{2}$ (not percentages) because that is INPE's official definition of deforestation. Thus, our definition of deforestation conforms to that monitored by PPCDAM. During 2001-2008, on average, $48 \mathrm{~km}^{2}$ was deforested (with a standard deviation of $110 \mathrm{~km}^{2}$ ) per municipality per year.

We use deforestation data for the period of 2001-2004 to construct a measure of preintervention municipality-level deforestation. Data for deforestation in 2004 likely do not capture pre-intervention deforestation adequately because it could be lower (or higher) in some municipalities due to year-specific measurement error. To mitigate this issue, we use the 20012004 period to compute a proxy of pre-intervention deforestation by estimating the following regression:

$$
D_{i t}=\delta_{0}+\delta_{1} \text { Time }+\sum_{i} \lambda_{i} \text { Time } * M_{i}+\sum_{i} \rho_{i} M_{i}+\zeta_{i t}
$$

where $D_{i t}$ is the measure of deforestation for municipality $i$ in year $t$, Time is a linear time trend, $M$ represents municipality dummies and $\zeta$ is an error term. We use the predicted value of deforestation in 2004 for each municipality as a measure of pre-intervention deforestation. Note that this strategy deals somewhat with year-specific measurement errors.

Figure 1 shows cross-sectional variation in pre-intervention deforestation across municipalities. This figure reveals that the levels of pre-intervention deforestation vary substantially, including within-state variation. For instances, the average pre-intervention deforestation of the municipalities in the top quartile of the pre-intervention deforestation distribution is 30 times higher than that of municipalities in the bottom quartile. The standard deviation in pre-intervention deforestation across municipalities in the sample is over $120 \mathrm{~km}^{2}$ (relative to a mean of $67 \mathrm{~km}^{2}$ ). As a result of this variation, as we shall see, different municipalities experienced differential changes in deforestation in the post-intervention period. This is the basis of our identification strategy. 


\subsection{Other Data}

We make use of information from other sources. In the appendix (section A1), we describe the construction of the municipality-level series for $\mathrm{PM}_{10}, \mathrm{CO}$ y $\mathrm{SO}_{2}$ for the period 1998-2008. In section A2 of the Appendix, we present the methodology for computing an annual index of crop prices at municipality level.

We also collect other municipality-level data on: $i$ ) fetal deaths for the period 1998-2008 from the Brazilian Mortality Information System; ii) BF beneficiary families for the period 2004-2008 from the Ministry of Social Development and Hunger Alleviation; iii) Gross Domestic Product (GDP) (available for 2000-2008 period); iv) agricultural production (available for 2000-2008 period) from the Brazilian Institute of Geography and Statistics (IBGE); v) child labor rates, illiteracy rates, and sanitation coverage from the 2000 Brazilian Demographic Census; vi) physicians per capita in 2000 from the Applied Economic Research Institute (IPEA); and finally vii) government spending share on education and health (available for 1999-2008 period) from the Finance Ministry.

\subsection{Additional Descriptive Statistics}

In this section, we present a graphical analysis of the main variables. To implement such an analysis, we classify municipalities into "Low and High" categories based on their preintervention deforestation. The Low (High) category consists of municipalities under (over) the 75 percentile of the pre-intervention deforestation. ${ }^{11}$ Figure 2 illustrates striking differences across municipalities in deforestation reductions. The municipalities in the "High" category experienced the most remarkable reductions, with deforestation declining from $207 \mathrm{~km}^{2}$ in 2004 to $87 \mathrm{~km}^{2}$ in 2008. In contrast, the reductions were less pronounced in the municipalities in the "Low" category, with deforestation ranging from $13 \mathrm{~km}^{2}$ in 2004 to $9 \mathrm{~km}^{2}$ in 2008. This provides informal evidence that conservation policy was particularly more successful in municipalities with higher pre-intervention deforestation.

Figure 3 shows that there are little changes in birth outcomes over time. The most noticeable changes are in the incidence of very low birth weight. In fact, the rate of very low

\footnotetext{
${ }^{11}$ The results of this analysis are qualitatively similar to the use of 80 , or $95^{\text {th }}$ percentiles as cut-off points.
} 
birth weight is getting worse over time, but the municipalities in the "High" group this birth outcome is getting less worse. There are no obvious trends in other birth outcomes across municipalities. Moreover, Figure 3 seems to show lack of parallel trends. For example, prematurity and very low birth weight show some sort of convergence before the program comes into place. As we will see in more detail below, such differential trends in maternal characteristics across municipalities are not statistically significant. Overall, it is difficult to infer any relationship between conservation policy and infant health from this informal analysis. $^{12}$

\section{Empirical Strategy}

To identify the impacts of the conservation policy, and thus the sharp reductions in deforestation, on birth outcomes, we estimate: ${ }^{13}$

$$
y_{i t}=\alpha+\beta \text { Post }_{t} x \text { BaseDeforestation }_{i}+\theta \mathrm{Z}_{\mathrm{it}}+\varphi \text { Trend }_{i t}+\eta_{i}+\mu_{t}+\xi_{i t}
$$

where $y_{i t}$ is the birth outcome of interest for the municipality $i$ in year $t$; Post $=1$ if year is 2005 or thereafter;BaseDeforestation ${ }_{i}$ is the pre-intervention municipality-level deforestation (computed as described in section 3.2), which is time-invariant; $\mathrm{Z}$ is a vector including control variables (e.g., percentage of births from married mother); Trend $_{i t}$ is a municipality-specific linear time trend; and $\eta_{i}$ and $\mu_{t}$ are municipality and year fixed effects, respectively. In all specifications, we use robust standard errors clustered at the micro-region

\footnotetext{
${ }^{12}$ Figure A1 displays trends in maternal characteristics over time. There is a declining trend in births from teenage and married mothers. Meanwhile, the percentage of newborns from mothers with over 12 years of education increases over time. A look at national trends of these variables suggests a similar pattern.

${ }^{13}$ The use of an Ordinary Least Squares (OLS) regression of the relationship between a birth outcome and deforestation cannot provide causality because deforestation may be endogenous. Omitted variables bias may lead to underestimates or overestimates of the true effect of changes in deforestation. Furthermore, deforestation indices are likely to be subject to measurement error, which would attenuate the OLS estimates, and the use of the fixed-effect estimator may exacerbate this problem. Not surprisingly, our estimates based on OLS regressions (available upon request from the authors) are inconclusive of a relationship between deforestation and infant health.
} 
level. ${ }^{14}$ In addition, the standard errors are corrected to take into account that baseline deforestation is the predicted value from Equation (1).

Model (2) is essentially a differences-in-differences setup that utilizes the fact that municipalities with higher pre-intervention deforestation were more likely to benefit from the intervention, to identify policy effects. Put differently, $\beta$ compares the change in birth outcomes between infants born before and after the intervention in municipalities that benefited more from the policy against the same change for infants born in municipalities with less pre-intervention deforestation. If the conservation policy led to lower incidence of prematurity and low birth weight, then we would expect to see negative coefficients on $\beta$.

Our identifying assumption is that in the absence of the PPCDAM, municipalities with different levels of pre-intervention deforestation would have experienced the same proportional changes in birth outcomes. Naturally, municipalities with different levels of pre-intervention deforestation may differ in ways that could affect birth outcomes. Any such differences that are time invariant will be captured by the municipality fixed effects in Equation (2). Only differential trends in unobserved factors across these municipalities would be a threat to the validity of this approach. The focus on municipalities located in states classified as priorities by the PPCDAM is a basic step to increase comparability across municipalities and limit potential differential trends. While we cannot directly test the identifying assumption, we can use data prior to the policy to test if, for each outcome of interest, municipalities with different levels of pre-intervention deforestation were on parallel trends prior to the policy. For this, we estimate the following regression:

$$
\begin{aligned}
y_{i t}=\alpha+\sum_{t=\text { initial year }}^{2004} \rho_{t} \text { year dummies } \\
\\
+v_{i t} \text { xBaseDeforestation } \text { Bum }_{i}+\omega_{i}+\lambda_{t}
\end{aligned}
$$

If trends across municipalities with different levels of pre-intervention deforestation were the same during the pre-treatment period, then they are likely to have been the same in

\footnotetext{
${ }^{14}$ In general, a micro-region is formed by a group of municipalities sharing the same border. On average, a microregion is made of seven municipalities.
} 
the post-treatment period in the absence of the PPCDAM. Figure A2 plots coefficients and 95\% confidence intervals from Equation (3) for deforestation and birth outcomes. All the coefficients on the pre-intervention years are insignificant, suggesting that the assumption of parallel trends might be valid. Note that this finding is not driven by large standard errors. For example, the coefficients for very low birth weight average -0.00017 . Relative to the mean, this implies an estimated effect of only $0.50 \%$ for the municipality at the 75 th percentile of the preintervention deforestation. To ensure that our model (2) identifies a policy effect separate from incidental municipality trends, we control for any differential preexisting trends by directly including municipality-specific linear time trends in all specifications.

We address several identification issues that emerge when following the specification (2). First, the pre-intervention deforestation is measured in $\mathrm{km}^{2}$ and this measure does not take into account that municipalities vary in size. At some level, it is obvious that municipality size matters. For instance, if smaller municipalities have better healthcare, then likelihood of differential trends driven by other factors may increase. We mitigate this by including the interaction between Post $_{t}$ and municipality size (in $\mathrm{Km}^{2}$ ) in all specifications. The inclusion of this variable controls for any differential trend across municipalities with different sizes. Furthermore, note that the inclusion of the municipality-specific linear time trends also deal, to a great extent, with this problem.

Second, PPCDAM's launch coincides with that of the BF, a conditional cash program that targets poor families in Brazil. Beneficiary families receive a monthly cash transfer (equivalent to $40 \%$ of the monthly minimum wage), conditional on school attendance and health center visits. Approximately $22.3 \%$ of Brazilian families were beneficiaries of the BF in 2010. For the Amazon, that figure corresponds to 30\%. Although all municipalities in our sample had beneficiary families in the period 2004-2008, there is great variation across municipalities. ${ }^{15}$ If the BF implementation is correlated with that of the PPCDAM, then it may lead to biased estimates of $\beta$. To deal with this issue, we directly included as a control in all specifications the interaction between Post $_{t}$ and the average percentage of beneficiary families. Since the BF program focused on the poorest municipalities, we also included in all

${ }^{15}$ For example, in 2008 the percentage of beneficiary families ranging from 3 to $60 \%$ across municipalities (Mean: 29.6; Standard Deviation: 11.09). 
specifications the interaction between Post and 2004 GDP. As robustness checks, we include other controls, such as interactions between Post and sanitation coverage, and illiteracy rates.

Third, the years after 2004 witnessed a marked reduction in crop prices (Assunção, Gandour, and Rocha 2015), which may have discouraged deforestation and affected household income. This would threaten the validity of our empirical strategy if municipalities with different levels of pre-intervention deforestation experience different changes in income due to reductions in crop prices. To address this issue, we control for an annual index of crop prices at municipality levels in all regressions.

Fourth, as we only observe birth outcomes for surviving (and presumably stronger) fetuses, a biased selection could arise. Any selection bias that results from using this select group is likely to lead to bias our estimates of the effect of PPCDAM towards zero. We address this issue in the robustness section, specifically by examining the effect of PPCDAM on the rate of fetal death. Statistically insignificant effects indicate that such bias is unlikely to play a major role.

We cannot directly test the validity of the identifying assumption. However, the sample selection of municipalities localized in states that were classified as priorities, the conditioning on municipality-specific linear time trends, and the use of the additional controls in all regressions make the validity of the empirical strategy reliable.

\section{Results}

\subsection{Main results}

We begin by examining the effects of the PPCDAM on deforestation. We estimate Equation (2) using deforestation as dependent variable (Table 2). Column (1) is based on a specification that adjusts only for municipality-specific linear time trends, as well as municipality and year fixed effects. Results from this specification indicate that municipalities with higher preintervention deforestation experienced larger reductions in deforestation during the postintervention period (coefficient estimated $=-0.32$ and statistically significant at $5 \%$ ). This finding is robust to controls for the annual index of crop prices, and the interactions between 
Post and municipality size, the mean fraction of BF beneficiaries, and the 2004 GDP (Column (2)). This provides reassuring evidence on the credibility of the analysis.

Column (3) presents yearly interaction terms for each of the post-policy years to investigate potential non-linear effects. All coefficients on these interactions are negative and significant. These results also suggest that policy had immediate impacts on deforestation. Overall, for the municipality in the 75th percentile of the pre-intervention deforestation distribution, conservation policy led to a $35-37 \%$ reduction in deforestation. These effects resemble those of other deforestation policies. For example, Jayachandran et al. (2016) find that a randomized controlled trial of the Payments for Ecosystem Services (PES) program reduced deforestation $40 \%$ in Uganda.

Table 3 presents the results for birth outcomes. Each Panel presents results from different birth outcome. The number of observations and the effects of the PPCDAM at the 75th percentile of pre-intervention deforestation are presented at the bottom of each Panel. Column (1) uses a specification that controls only for municipality-specific linear time trends as well as municipality and year fixed effects, while the remaining columns correspond to specifications that include an additional set of controls.

The result from column (1) in Panel A reveals a statistically significant and negative estimate of the parameter of interest. Given that the rate of very low birth weight is increasing over time (as shown in Figure 3), the estimated coefficient indicates that municipalities with higher pre-intervention deforestation experienced lower increases in very low birth weight rates. This estimated coefficient is insensitive to adding other controls. For the municipality in the 75th percentile of the pre-intervention deforestation distribution, deforestation control policy is associated with $18-20 \%$ reduction in the rate of very low birth weight. Results from Panel B show that the conservation policy is associated with reductions in low birth weight incidence, though the estimates are imprecise and statistically insignificant.

The results from Panel $\mathrm{C}$ show a statistically significant and negative coefficient, implying that conservation policy contribute to reduce the incidence of extreme prematurity. Although the effect is less precisely estimated with the inclusion of additional controls, it 
remains statistically significant at $5 \%$. For prematurity, we also found a negative coefficient (Panel D) across specifications, but very imprecisely estimated and statistically insignificant.

In Table A1, we estimate yearly interaction terms for each of the post-policy years to examine possible dose-response effects. These regressions replicate the patterns found before, indicating that deforestation control policy is associated with reduced risk of poor birth outcomes. The coefficients on these interactions are similar relative to the baseline ones, although some are imprecisely estimated.

Table 4 investigates the gender specificity of the findings from Table 3 . We estimate the complete specification for boys and girls separately. The results suggest that conservation policy had a much greater impact on male fetuses. For very low birth weight, boys from the municipality in the 75th percentile of the pre-intervention deforestation distribution experienced a $35.4 \%$ reduction. For girls in the same municipality such a reduction is estimated at $10 \%$. For extreme prematurity, we find that, for the municipality in the 75 th of preintervention deforestation, policy led to 53 and $25 \%$ reductions for boys and girls, respectively (column (3)). Although the estimates for premature births are imprecisely estimated (column (4)), they still suggest more pronounced effects on male fetuses.

That sex discrimination accounts for these differences seems implausible given that gender bias at early ages is not considered significant in Brazil. The sex ratio at birth, which has emerged as an indicator of sex-discrimination at early ages, is in the normal range 104-107 in our sample. Rather, our results are consistent with the literature on fragile males, which attributes gender differences to differences in ability to produce nutrients in the placenta. That attribution is supported by studies documenting gender-specific effects of different shocks during pregnancy (Ross and Desai 2005).

Taken together, the evidence suggests that the conservation policy had positive effects on infant health. Furthermore, such effects seem to be heterogeneous across the distribution of birth outcomes. In particular, newborns in the bottom of birth outcome distribution benefited more from this policy. 


\subsection{Channels}

Our final effort is to uncover the channels governing the relationship between reduced deforestation and infant health. We begin by assessing whether the policy affected air pollution, given the well-documented evidence that pollutants such as $\mathrm{CO}$ and $\mathrm{PM}_{10}$ have harmful effects on fetal health (Currie, Neidell, and Schmieder 2009; Currie and Walker 2011; Glinianaia et al. 2004).

In Table 5, we estimate the specification of Equation (2) using $\mathrm{CO}, \mathrm{PM}_{10}$, and $\mathrm{SO}_{2}$ as dependent variables. All specifications included controls for crop prices, and the interactions between the Post and municipality size, 2004 GDP, and the average percentage of BF beneficiaries. Overall, the results indicate that policy conservation is associated with significant reductions in air pollution. For the municipality in the 75th percentile of the pre-intervention deforestation, the reductions in the levels of $\mathrm{CO}, \mathrm{PM}_{10}$ and $\mathrm{SO}_{2}$ were 17.2, 17.6 and 8.8 percent, respectively. The finding that PPCDAM led to a 35\% reduction in deforestation for the municipality in the 75th percentile of pre-intervention deforestation suggests that elasticities of $\mathrm{CO}, \mathrm{PM}_{10}$, and $\mathrm{SO}_{2}$ with respect to deforestation are $0.54,0.55$, and 0.27 , respectively. Assuming fire-damaged areas represent $50 \%$ of the area annually deforested (Morton et al. 2011), crude estimates of the elasticities of $\mathrm{CO}, \mathrm{PM}_{10}$, and $\mathrm{SO}_{2}$ with respect to biomass burning would be $1.08,1.10$, and 0.54 , respectively. These estimates are in line with previous. For example, Sillapapiromsuk et al (2013) find an elasticity of $\mathrm{PM}_{10}$ with respect to biomass burning of 1.04 .

To evaluate the quantitative significance of the reductions in air pollution for infant health, we combine the results from tables 2 and 5. These estimates suggest, for example, that a $1 \%$ reduction in $\mathrm{CO}$ lowers incidence of low birth weight $0.20 \%$. While imprecisely estimated, this point estimate is quite similar to that of other studies. For instance, Currie and Walker (2011) suggest an elasticity of low birth weight with respect to CO of 0.27 . The caveat to our analysis is that our estimates may reflect also the importance of other potential mechanisms. Thus, this exercise should be viewed cautiously. 
In Table 6, we empirically investigated whether the policy affected socioeconomic outcomes such as agricultural production and income. In the absence of a direct measure of household income, we use GDP at the municipality-level as a proxy. Column (1) reveals a positive estimate of the parameter of interest, suggesting that municipalities with higher preintervention deforestation experienced larger increases in GDP. However, such a coefficient is not statistically significant. We also find that conservation policy is no associated with changes in agricultural production or crop production (Columns (2)-(3)). Overall, results indicate little evidence that the conservation policy is associated with changes in agricultural activity or income. This finding is consistent with Jayachandran et al (2016), who show that the PES in Uganda had no socioeconomic impacts.

\subsection{Robustness of Findings}

We performed a number of robustness checks designed to examine the validity of our identification strategy. Table A2 explores a variety of alternative specifications. Column 1 replicates our main estimates, while column 2 shows the results of a specification that includes government spending share on health and education as control variables. These additional controls could capture different dimensions of local policy correlated with both the implementation of the PPCDAM and the BF program. The inclusion of these variables slightly increases the estimated coefficients of interest (in absolute value). Columns (3)-(7) control for interactions between Post and child labor rate, illiteracy rate, sanitation coverage and physicians per capita. In some cases, the inclusion of these variables leads to slightly larger estimates. In particular, the estimated effect on low birth weight tends to be more negative and statistically significant. Overall, our estimates are robust to including these additional controls.

We also check for possible mean reversion by including a one-year lagged dependent variable $\left(y_{i t-1}\right)$ as a control (Table A3). The inclusion of this variable hardly changes our results. However, the OLS estimator in column (2) is inconsistent because of the presence of the lagged dependent variable on the right-hand side. Column (3) estimates the same model 
using the Arellano-Bond GMM (Generalized Moment Method) dynamic panel estimator. In most cases, this leads to more negative coefficients than in our baseline specification. ${ }^{16}$

In the Table A4, we investigate the potential bias from fetus selection. In column (1), we estimate the specification of Equation (2) using the fetal death rate as the dependent variable. If the deforestation control policy reduced fetal death, then we should observe a negative and statistically significant estimate on the coefficient of interest. The estimate is indeed negative, but not statistically different from zero. However, it is exercise is imperfect because fetal death is registered only for pregnancies that were long enough. As a further check, we examine whether the policy had significant effects on sex ratio at birth. If policy reduced significantly fetal deaths, then we should see increases in the sex ratio in favor of boys. The results show a positive coefficient, but statistically insignificant (Column (2)). Put together, this evidence suggests that the bias from fetus selection is likely to be small.

We also test whether characteristics of mothers in municipalities with higher preintervention deforestation change over time in a way that is comparable to those municipalities with less pre-intervention deforestation. Columns (3)-(5) from Table A4 show the results of a natural falsification test: we estimate the baseline specification using maternal characteristics as dependent variables. To the extent that our estimates do not reflect the compositional changes in births, the PPCDAM should not predict maternal characteristic changes. This is exactly what we find. We also find a statistically insignificant relationship between PPCDAM and pregnancies per capita. This provides further evidence that compositional changes in births have not taken place.

We performed further robustness tests (not shown). ${ }^{17}$ The use of 2004 deforestation as measure of pre-intervention deforestation reduces, in magnitude, the estimated coefficients of interest, although the results are qualitatively similar. Our results are also robust to using the average deforestation for the period 2001-2004 as measure of pre-intervention deforestation. Estimates are also unaffected when using the interaction between Post and the percentage of $2004 \mathrm{BF}$ beneficiaries (rather that the average percentage of BF beneficiaries) as a control. Our

\footnotetext{
${ }^{16}$ These results are broadly similar to those derived from the Blundell-Bond's GMM estimator.

${ }^{17}$ These further robustness exercises are available upon author request.
} 
results are also robust to excluding extremely high or low values of pre-intervention deforestation. ${ }^{18}$ The results are qualitatively similar to using standard errors clustered at the municipal level (rather than micro-region level). The inclusion of quadratic and cubic terms of the interaction between Post and municipality size does not alter our estimates. Finally, we examine whether our results are affected when excluded the year 2000 of this analysis. In that year, it appears that there is some systematic deviance in birth outcomes across municipalities with different levels of pre-intervention deforestation (as can be observed in Figure 3). The estimates dropping this year indicate that our findings results are not driving by this deviance.

\section{Final Remarks}

This study provides estimates of the externalities of a deforestation control policy in infant health. Indeed, this study finds that the Brazilian conservation policy launched in 2004 had positive effects on infant health. Specifically, we find that the conservation policy is associated with reductions in the incidence of very low birth weight and extreme prematurity. These findings are generally larger in magnitude for boys, which reinforces the idea that a genderspecific analysis can be useful when assessing effects of in utero shocks. The patterns in our data suggest that improvements in air pollution were an important pathway.

One way to assess the magnitude of the estimated impacts is to compare the effects of conservation policy with previous estimates of the effect of other environmental risk factors. Using exogenous changes in air pollution, Currie and Walker (2011) showed that the reductions in air pollution resulted in a $10 \%$ reduction in the incidence of low birth weight. In a recent study, Currie and Schwandt (2014) found that increases in the toxic dust and smoke due to the terrorist attack of September 11, 2001 on the World Trade Center increased the incidence of prematurity and low birth weight at $27 \%$ and $13 \%$, respectively. Almond, Chay, and Lee (2005) showed that smoking during pregnancy increases the incidence of low birth weight by $4 \%$. Compared to our estimates, the conservation policy had smaller effects on birth weight and prematurity.

\footnotetext{
${ }^{18}$ We define extremely low (high) deforestation as those municipalities (over the 99th) under the 1th percentile of the distribution of pre-intervention deforestation.
} 
The findings from this study have important implications for policy and contribute to the growing literature on the importance of a healthy fetal environment. Our findings point to a group - infant boys - that is particularly vulnerable to changes in deforestation. The costbenefit analyses of conservation policies should take into account this. As such, our findings provide additional justification for interventions that aim to prevent and control deforestation. Given previous studies documenting that poor fetal health has adverse consequences on education, life expectancy and productivity, our results suggest that deforestation control policies could reduce inequality and have lasting benefits in accumulation of human capital.

We should point out that there are various limitations to this study that should be addressed in future work. The most important one is that, given the data limitations, our estimates do not allow us to disentangle the channels that underpin the relationship between the conservation policy and infant health. Although, the evidence suggests that changes in air pollution are likely to be an important mechanism, we cannot rule out the possibility that other factors play a role. Our methodology provides only suggestive evidence of the combined effects of these channels. Future studies should empirically investigate the malaria risk channel. Data limitations do not allowed defining deforestation to exclude urbanization. This could be relevant given that previous studies document that urbanization leads to decreased risk of malaria. Moreover, it is not clear whether one should expect the estimated effects of reductions in deforestation to be the same across space and time as they may depend on the average health and nutritional status of pregnant women and specific environmental characteristics of each country or region. Setting aside the issue of generalizability, the fact that debates on conservation policies will become increasingly common implies that understanding the effects of controlling deforestation is an important question per se. We believe that future studies linking later socio-economic outcomes with birth records could yield even greater insights into the long-term impacts of Brazil's conservation policy.

\section{References}

Almond, Douglas, Kenneth Y Chay, and David S Lee. 2005. "The Costs of Low Birth Weight." The Quarterly Journal of Economics 120 (3 ): 1031-83. 
Almond, Douglas, Lena Edlund, and Mårten Palme. 2009. "Chernobyl's Subclinical Legacy: Prenatal Exposure to Radioactive Fallout and School Outcomes in Sweden." The Quarterly Journal of Economics 124 (4 ): 1729-72.

Almond, Douglas, and Bhashkar Mazumder. 2011. "Health Capital and the Prenatal Environment: The Effect of Ramadan Observance during Pregnancy." American Economic Journal: Applied Economics 3 (4): 56-85.

Arceo, Eva, Rema Hanna, and Paulina Oliva. 2015. "Does the Effect of Pollution on Infant Mortality Differ Between Developing and Developed Countries? Evidence from Mexico City.” The Economic Journal. doi: 10.1111/ecoj.12273.

Assunção, Juliano, Clarissa Gandour, and Rudi Rocha. 2015. "Deforestation Slowdown in the Brazilian Amazon: Prices or Policies?" Environment and Development Economics 20 (6):697-722.

Barreca, Alan I. 2010. "The Long-Term Economic Impact of In Utero and Postnatal Exposure to Malaria." Journal of Human Resources 45 (4 ): 865-92.

Chang, Simon, Belton Fleisher, Seonghoon Kim, and Shi-yung Liu. 2014. "Long-Term Health Effects of Malaria Exposure around Birth: Evidence from Colonial Taiwan." Economic Development and Cultural Change 62 (3): 519-36.

Crimmins, Eileen M, and Caleb E Finch. 2006. "Infection, Inflammation, Height, and Longevity." Proceedings of the National Academy of Sciences of the United States of America 103 (2): 498-503.

Currie, Janet. 2009. "Healthy, Wealthy, and Wise: Socioeconomic Status, Poor Health in Childhood, and Human Capital Development." Journal of Economic Literature 47 (1): $87-122$.

Currie, Janet, and Matthew Neidell. 2005. "Air Pollution and Infant Health: What Can We Learn from California's Recent Experience?” The Quarterly Journal of Economics 120 (3 ): 1003-30.

Currie, Janet, Matthew Neidell, and Johannes F Schmieder. 2009. "Air Pollution and Infant Health: Lessons from New Jersey." Journal of Health Economics 28 (3): 688-703.

Currie, Janet, and Reed Walker. 2011. "Traffic Congestion and Infant Health: Evidence from E-ZPass." American Economic Journal: Applied Economics 3 (1): 65-90.

Currie, Janet, and Hannes Schwandt. 2014. "The 9/11 Dust Cloud and Pregnancy Outcomes: A Reconsideration”, Working Paper, National Bureau of Economic Research.

Eriksson, Johan G, Eero Kajantie, Clive Osmond, Kent Thornburg, and David J P Barker. 2010. "Boys Live Dangerously in the Womb." American Journal of Human Biology 22 (3): $330-35$. 
Ferreira, Joaquim, Luis Ribera, and Mark Horridge. 2015. "Deforestation Control and Agricultural Supply in Brazil." American Journal of Agricultural Economics 97 (2 ): 589 601.

Frankenberg, Elizabeth, Douglas McKee, and Duncan Thomas. 2005. "Health Consequences of Forest Fires in Indonesia." Demography 42 (1): 109-29.

Glinianaia, Svetlana V, Judith Rankin, Ruth Bell, Tanja Pless-Mulloli, and Denise Howel. 2004. "Particulate Air Pollution and Fetal Health: A Systematic Review of the Epidemiologic Evidence." Epidemiology 15 (1): 36-45.

Garg, Teevrat. 2014. "Public Health Effects of Natural Resource Degradation: Evidence from Indonesia." Paper presented at the 2014 World Congress of Environmental and Resource Economists, Turkey, June 28-July 2.

Guyatt, Helen L, and Robert W Snow. 2004. "Impact of Malaria during Pregnancy on Low Birth Weight in Sub-Saharan Africa." Clinical Microbiology Reviews 17 (4 ): 760-69.

Hahn, Micah B, Ronald E Gangnon, Christovam Barcellos, Gregory P Asner, and Jonathan A Patz. 2014. "Influence of Deforestation, Logging, and Fire on Malaria in the Brazilian Amazon." PLoS ONE 9 (1): 1-8.

Huynh, Bich-Tram, Nadine Fievet, Gildas Gbaguidi, Sébastien Dechavanne, Sophie Borgella, Blaise Guézo-Mévo, Achille Massougbodji, Nicaise Tuikue Ndam, Philippe Deloron, and Michel Cot. 2011. "Influence of the Timing of Malaria Infection during Pregnancy on Birth Weight and on Maternal Anemia in Benin." The American Journal of Tropical Medicine and Hygiene 85 (2): 214-20.

Isen, Adam, Maya Rossin-Slater, and W. Reed Walker. 2014. "Every Breath You Take -Every Dollar You'll Make: The Long-Term Consequences of the Clean Air Act of 1970". Working Paper, National Bureau of Economic Research

Jayachandran, Seema, Joost de Laat, Eric F. Lambin, and Charlotte Y. Stanton. 2016. "Cash for Carbon: A Randomized Controlled Trial of Payments for Ecosystem Services to Reduce Deforestation". Working Paper, National Bureau of Economic Research.

Kraemer, Sebastian. 2000. “The Fragile Male.” BMJ: British Medical Journal 321 (7276). BMJ: 1609-12.

Menendez, Clara, and Alfredo Mayor. 2007. "Congenital Malaria: The Least Known Consequence of Malaria in Pregnancy." Seminars in Fetal and Neonatal Medicine 12 (3): 207-13.

Morton, Douglas C, Ruth S DeFries, Jyoteshwar Nagol, Carlos M Souza Jr., Eric S Kasischke, George C Hurtt, and Ralph Dubayah. 2011. "Mapping Canopy Damage from Understory Fires in Amazon Forests Using Annual Time Series of Landsat and MODIS Data." Remote Sensing of Environment 115 (7): 1706-20. 
Olson, Sarah H, Ronald Gangnon, Guilherme Abbad Silveira, and Jonathan A Patz. 2010. "Deforestation and Malaria in Mâncio Lima County, Brazil." Emerging Infectious Disease Journal 16 (7): 1108.

Poespoprodjo, Jeanne R, Afdal Hasanuddin, Wendelina Fobia, Paulus Sugiarto, Enny Kenangalem, Daniel A Lampah, Emiliana Tjitra, Ric N Price, and Nicholas M Anstey. 2010. "Severe Congenital Malaria Acquired in Utero." The American Journal of Tropical Medicine and Hygiene 82 (4): 563-65.

Ross, Michael G, and Mina Desai. 2005. "Gestational Programming: Population Survival Effects of Drought and Famine during Pregnancy." American Journal of Physiology Regulatory, Integrative and Comparative Physiology 288 (1): R25-33.

Sanders, Nicholas J. 2012. "What Doesn't Kill You Makes You Weaker: Prenatal Pollution Exposure and Educational Outcomes ." Journal of Human Resources 47 (3 ): 826-50.

Sarr, Demba, Laurence Marrama, Alioune Gaye, Jean Dangou, Makhtar Niang, Odile Mercereau-Puijalon, Jean Lehesran, and Ronan Jambou. 2006. "High Prevalence of Placental Malaria and Low Birth Weight in Sahelian Periurban Area." The American Journal of Tropical Medicine and Hygiene 75 (1): 171-77.

Sastry, Narayan. 2002. "Forest Fires, Air Pollution, and Mortality in Southeast Asia." Demography 39 (1): 1-23..

Seaton, A, D Godden, W MacNee, and K Donaldson. 1995. "Particulate Air Pollution and Acute Health Effects." The Lancet 345 (8943): 176-78.

Sillapapiromsuk, Sopittaporn, Somporn Chantara, Urai Tengjaroenkul, Sukon Prasitwattanaseree, and Tippawan Prapamontol. 2013. "Determination of PM10 and its ion composition emitted from biomass burning in the chamber for estimation of open burning emissions". Chemosphere 93: 1912-1919.

Venkataramani, Atheendar S. 2012. "Early Life Exposure to Malaria and Cognition in Adulthood: Evidence from Mexico." Journal of Health Economics 31 (5): 767-80.

Vittor, Yomiko, Robert Gilman, James Tielsch, Gregory Glass, Tim Shields, Wagner LOozano, Viviana Pinedo-Cancino, and Jonathan Patz. 2006. "The Effect of Deforestation on the Human-Bitting Rate Anopheles Darlingi, the Primary Vector of Falciparum Malaria in the Peruvian Amazon." The American Journal of Tropical Medicine and Hygiene 74 (1): 3-11.

Vittor, Yomiko, William Pan, Robert Gilman, James Tielsch, Gregory Glass, Tim Shields, Wagner Sánchez-Lozano, et al. 2009. "Linking Deforestation to Malaria in the Amazon: Characterization of the Breeding Habitat of the Principal Malaria Vector, Anopheles Darlingi." The American Journal of Tropical Medicine and Hygiene 81 (1): 5-12. 
Yokelson, R J, T Karl, P Artaxo, D R Blake, T J Christian, D W T Griffith, A Guenther, and W M Hao. 2007. "The Tropical Forest and Fire Emissions Experiment: Overview and Airborne Fire Emission Factor Measurements." Atmos. Chem. Phys. 7 (19): 5175-96. 
Figure 1. Pre-intervention deforestation

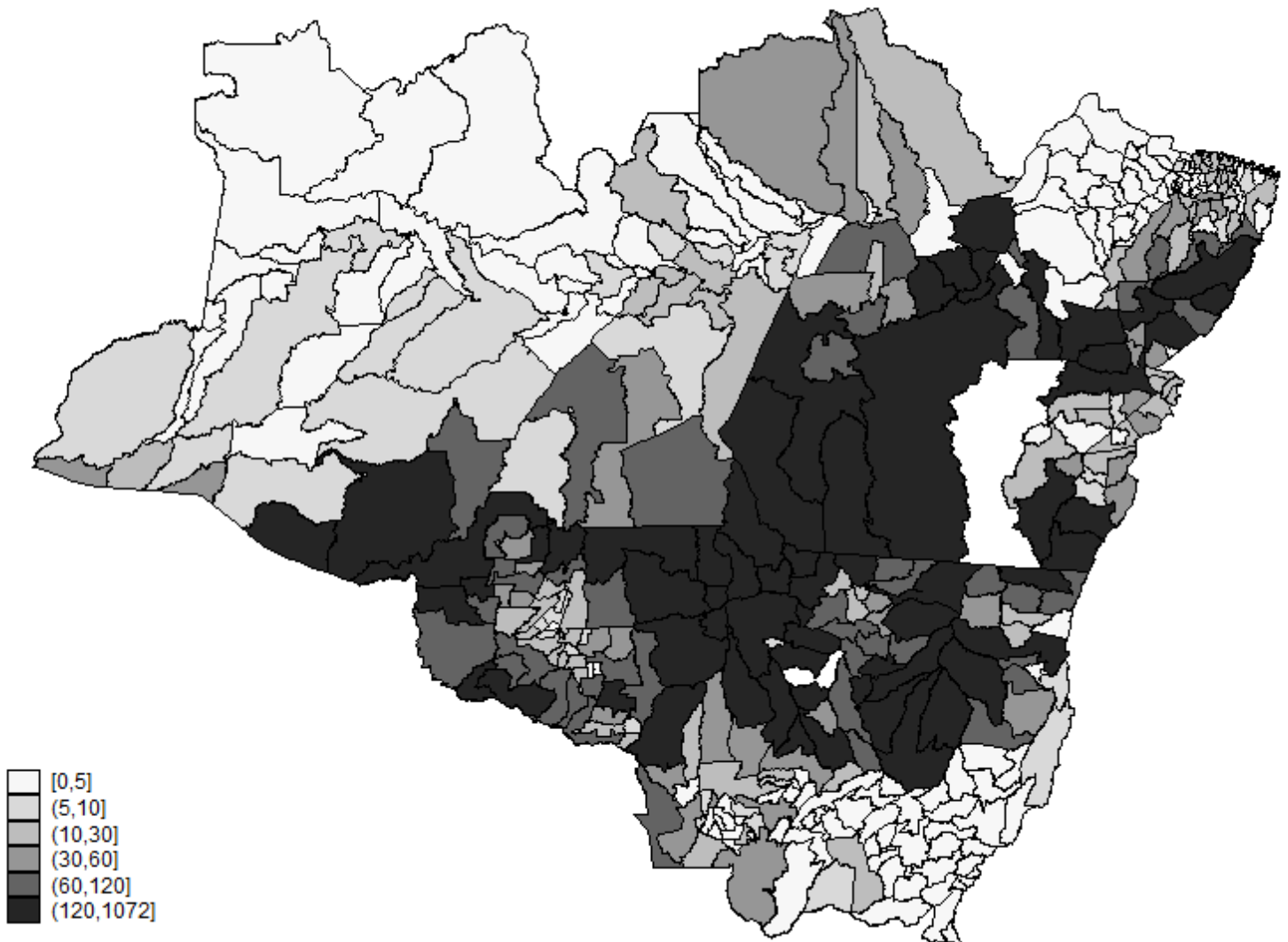

Note. This map displays the pre-intervention deforestation in $\mathrm{km} 2$ for each municipality in the sample 
Figure 2. Deforestation Trends, 2001-2008

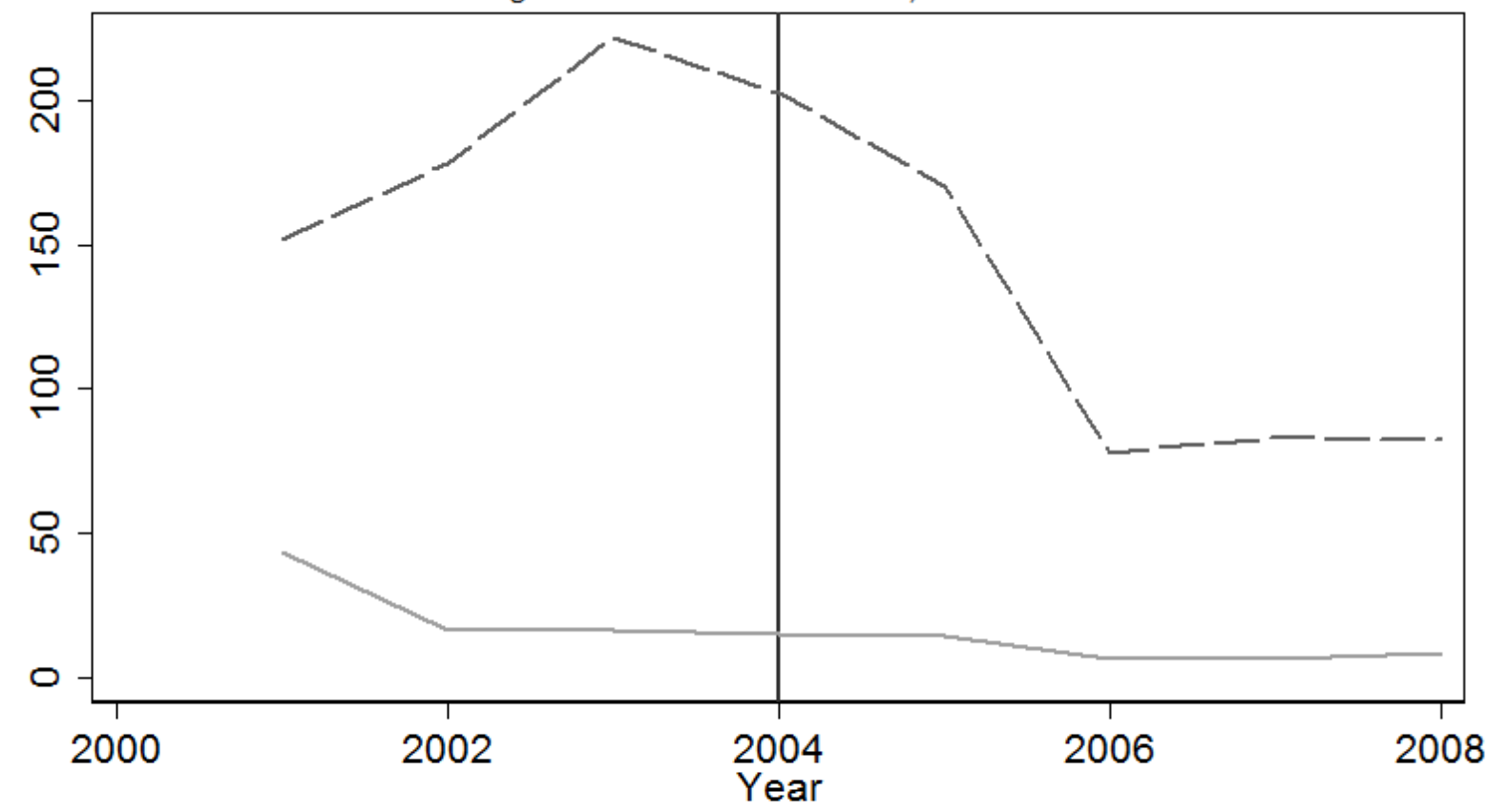

Note. Deforestation is defined as the annual forest cleared in $\mathrm{km} 2$. The municipalities were classified into Low and High categories based on their pre-intervention deforestation. The Low (High) category consists of municipalities under (over) the 75 percentile of the pre-intervention deforestation.

Figure 3. Trends in Birth Outcomes
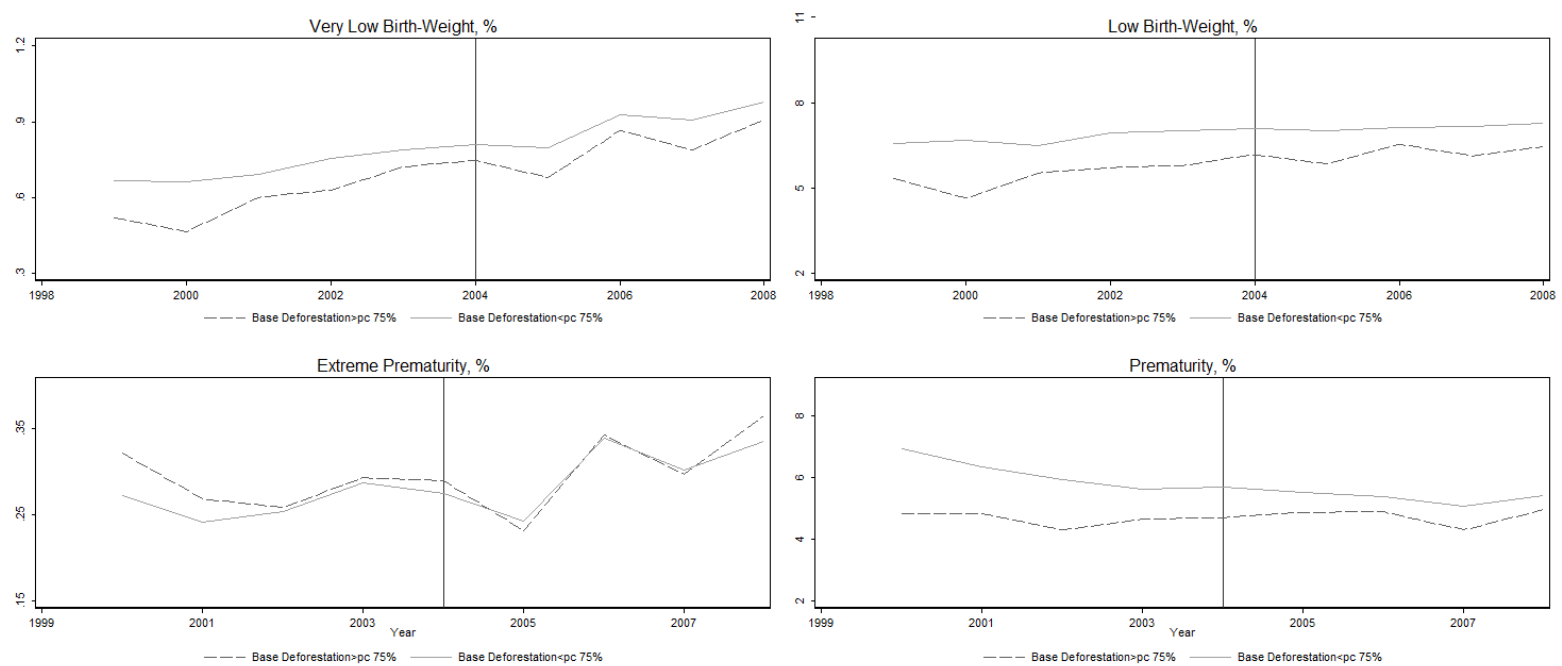

Note. Deforestation is defined as the annual forest cleared in $\mathrm{km} 2$. The municipalities were classified into Low and High categories based on their preintervention deforestation. The Low (High) category consists of municipalities under (over) the 75 percentile of the pre-intervention deforestation. 
TABLE 1

\section{SUMMARY STATISTICS}

\begin{tabular}{lcccc}
\hline \hline & $\begin{array}{c}\text { Number of } \\
\text { Municipalities }\end{array}$ & Number of & Mean & Dtandard \\
& 396 & Observations & & \\
Number of births & 396 & 4,356 & 715.86 & 2470.45 \\
Very low birth-weight rate & 396 & 4,310 & 0.60 & 0.69 \\
Low birth-weight rate & 396 & 4,310 & 5.89 & 2.43 \\
Extreme prematurity rate & 396 & 3,545 & 0.27 & 0.48 \\
Prematurity rate & 396 & 3,545 & 6.12 & 11.78 \\
Maternal Characteristic: & 396 & & & \\
Teenage mother rate & 396 & 4,307 & 31.45 & 6.08 \\
Education years over 12 rate & & 4,310 & 5.55 & 5.24 \\
Married mother rate & & 3,545 & 30.14 & 15.19 \\
\hline \hline
\end{tabular}

Note. Yearly observations by municipality from 1998 to 2008 . The rates are expressed by 100 live births. 
TABLE 2

EFFECTS OF PPCDAM ON DEFORESTATION

\begin{tabular}{|c|c|c|c|}
\hline & (1) & $(2)$ & (3) \\
\hline Post $x$ BaseDeforestation & $\begin{array}{c}-0.329 \\
{[0.151]^{* *}}\end{array}$ & $\begin{array}{c}-0.309 \\
{[0.153]^{* *}}\end{array}$ & \\
\hline Year $2005 x$ BaseDeforestation & & & $\begin{array}{c}-0.314 \\
{[0.188]^{*}}\end{array}$ \\
\hline Year $2006 x$ BaseDeforestation & & & $\begin{array}{c}-0.822 \\
{[0.192]^{* * *}}\end{array}$ \\
\hline Year $2007 x$ BaseDeforestation & & & $\begin{array}{c}-0.887 \\
{[0.27]^{* * *}}\end{array}$ \\
\hline Year $2008 x$ BaseDeforestation & & & $\begin{array}{c}-1.047 \\
{[0.34]^{* * *}}\end{array}$ \\
\hline Effect at 75th Percentile of BaseDeforestation, $(\%)$ & -37.9 & -35.73 & \\
\hline Observations & 3,168 & 3,168 & 3,168 \\
\hline Additional controls & No & Yes & Yes \\
\hline Municipality time trend & Yes & Yes & Yes \\
\hline
\end{tabular}

Note. The dependent variable is deforestation in $\mathrm{km}^{2}$. Effect at 75th percentile of BaseDeforestation is computed by multiplying the pre-intervention deforestation for the municipality in the 75th percentile of the pre-intervention deforestation by the coefficient on Post $x$ BaseDeforestation, and dividing the resulting value by the mean of dependent variable. All regressions include municipality and year fixed effects Additional controls include the annual index of crop prices, and the interactions between Post and municipality size, the average percentage of Bolsa Family beneficiaries, and the 2004 GDP. Robust standard errors in brackets are clustered at the microregion level. Significance: $* \mathrm{p}<0.10 * * \mathrm{p}<0.05, * * * \mathrm{p}<0.01$. 
TABLE 3

EFFECTS OF PPCDAM ON INFANT HEALTH

(1)

(2)

(3)

(4)

(5)

Panel A: Dependent variable is Very Low Birth-Weight Rate

Post $x$ BaseDeforestation

$\begin{array}{ccccc}-0.00049 & -0.000601 & -0.000505 & -0.00052 & -0.00054 \\ {[0.00022]^{* *}} & {[0.00025]^{* *}} & {[0.00025]^{* *}} & {[0.00025]^{* *}} & {[0.00026]^{* *}} \\ -18.54 & -22.43 & -18.87 & -19.51 & -20.33 \\ 4,310 & 4,310 & 4,310 & 4,310 & 4,307\end{array}$

Effect at 75th Percentile of BaseDeforestation, (\%) Observations

Panel B: Dependent variable is Low Birth-Weight Rate

Post $x$ BaseDeforestation

$\begin{array}{ccccc}-0.00053 & -0.00084 & -0.00067 & -0.00069 & -0.00083 \\ {[0.00054]} & {[0.00063]} & {[0.00077]} & {[0.00078]} & {[0.00074]} \\ -2.12 & -3.31 & -2.65 & -2.74 & -3.29 \\ 4,310 & 4,310 & 4,310 & 4,310 & 4,307\end{array}$

Effect at 75th Percentile of BaseDeforestation, (\%) Observations

Panel C: Dependent variable is Extreme Prematurity Rate

Post $x$ BaseDeforestation

Effect at 75th Percentile of BaseDeforestation, (\%) Observations

$$
\begin{array}{ccccc}
-0.00044 & -0.00048 & -0.00045 & -0.00048 & -0.00048 \\
{[0.00020]^{* *}} & {[0.00022]^{* *}} & {[0.00021]^{* *}} & {[0.00022]^{* *}} & {[0.00022]^{* *}} \\
-35.5 & -38.64 & -36.33 & -38.80 & -38.72 \\
3,545 & 3,545 & 3,545 & 3,545 & 3,544
\end{array}
$$

Panel D: Dependent variable is Prematurity Rate
Post $x$ BaseDeforestation

Effect at 75th Percentile of BaseDeforestation, (\%) Observations

Post $x$ Municipal size

Bolsa Familia

Crop price index

Maternal characteristics

Municipality time trend

\begin{tabular}{ccccc}
-0.0012 & -0.0019 & -0.0027 & -0.0025 & -0.0027 \\
{$[0.0016]$} & {$[0.0016]$} & {$[0.0018]$} & {$[0.0019]$} & {$[0.0020]$} \\
-4.99 & -8.06 & -11.52 & -10.73 & -11.20 \\
3,545 & 3,545 & 3,545 & 3,545 & 3,544 \\
\hline No & Yes & Yes & Yes & Yes \\
No & No & Yes & Yes & Yes \\
No & No & No & Yes & Yes \\
No & No & No & No & Yes \\
Yes & Yes & Yes & Yes & Yes \\
\hline
\end{tabular}

Note. Effect at 75th percentile of BaseDeforestation is computed by multiplying the pre-intervention deforestation for the municipality in the 75th percentile of the pre-intervention deforestation by the coefficient on Post $x$ BaseDeforestation, and dividing the resulting value by the mean of dependent variable. Bolsa Familia includes the interactions between Post and the average percentage of Bolsa Family beneficiaries, and 2004 GDP. All regressions include municipality and year fixed effects. Maternal characteristics include: $\%$ of teenage mother, $\%$ of married mother, and \% of Mother with Education years $>12$. Robust standard errors in brackets are clustered at the micro-region level. Significance: $* \mathrm{p}<0.10 * * \mathrm{p}<0.05, * * * \mathrm{p}<0.01$. 
TABLE 4

EFFECTS OF PPCDAM ON INFANT HEALTH BY GENDER

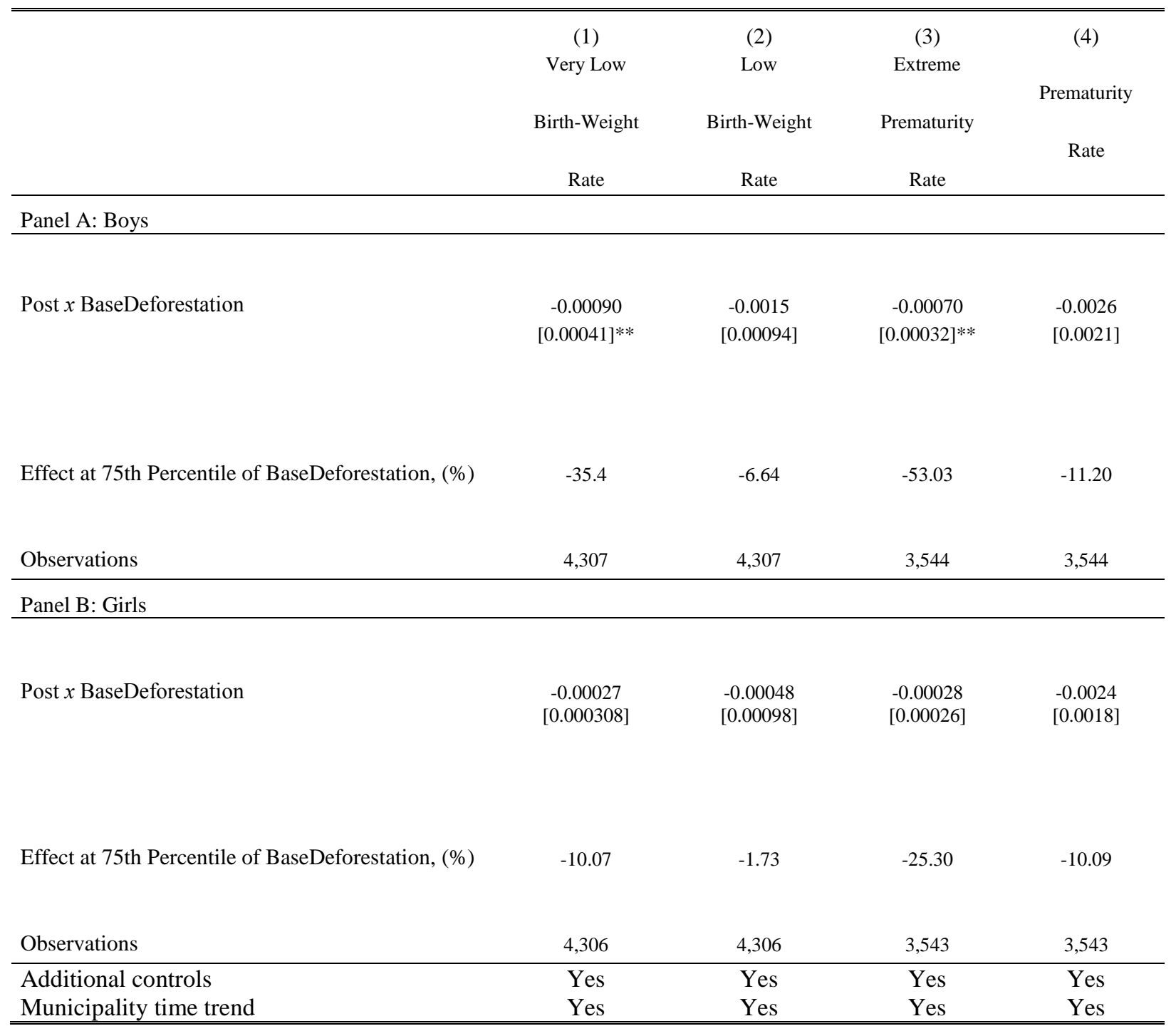

Note. Effect at 75th percentile of BaseDeforestation is computed by multiplying the pre-intervention deforestation for the municipality in the 75th percentile of the pre-intervention deforestation by the coefficient on Post $x$ BaseDeforestation, and dividing the resulting value by the mean of dependent variable. Aditional controls include: interactions between Post and the average percentage of Bolsa Family beneficiaries, and 2004 GDP; fixed effects for municipality and year; $\%$ of teenage mother, $\%$ of married mother, and $\%$ of Mother with Education years $>12$. Robust standard errors in brackets are clustered at the micro-region level. Significance: $* \mathrm{p}<0.10 * * \mathrm{p}<0.05$, $* * * \mathrm{p}<0.01$. 
TABLE 5

EFFECTS OF PPCDAM ON AIR POLLUTION

\begin{tabular}{|c|c|c|c|c|c|c|}
\hline & $\begin{array}{l}\mathrm{CO} \\
\text { (1) }\end{array}$ & $\begin{array}{l}\mathrm{CO} \\
(2)\end{array}$ & $\begin{array}{c}\mathrm{PM}_{10} \\
(3)\end{array}$ & $\begin{array}{c}\mathrm{PM}_{10} \\
(4)\end{array}$ & $\begin{array}{c}\mathrm{SO}_{2} \\
(5)\end{array}$ & $\begin{array}{c}\mathrm{SO}_{2} \\
(6)\end{array}$ \\
\hline \multirow[t]{2}{*}{ Post $x$ BaseDeforestation } & -0.0008 & & -0.00082 & & -0.00041 & \\
\hline & {$[0.00040]^{* *}$} & & {$[0.00041]^{* *}$} & & {$[0.00023]^{*}$} & \\
\hline \multirow[t]{2}{*}{ Year $2005 x$ BaseDeforestation } & & -0.0005 & & -0.0007 & & -0.0003 \\
\hline & & {$[0.0003]^{*}$} & & {$[0.0003]^{*}$} & & [0.0002] \\
\hline \multirow[t]{2}{*}{ Year $2006 x$ BaseDeforestation } & & -0.00231 & & -0.00232 & & -0.00157 \\
\hline & & {$[0.0009]^{* * *}$} & & {$[0.0009]^{* * *}$} & & {$[0.0006]^{* * *}$} \\
\hline \multirow[t]{2}{*}{ Year $2007 x$ BaseDeforestation } & & 0.00419 & & -0.00424 & & -0.00236 \\
\hline & & {$[0.0011]^{* * *}$} & & {$[0.0012]^{* * *}$} & & {$[0.0008]^{* * *}$} \\
\hline \multirow[t]{2}{*}{ Year $2008 x$ BaseDeforestation } & & -0.00489 & & -0.00495 & & -0.00289 \\
\hline & & {$[0.0013]^{* * *}$} & & {$[0.0013]^{* * *}$} & & {$[0.0009]^{* * *}$} \\
\hline \multicolumn{7}{|l|}{ Effect at $75^{\text {th }}$} \\
\hline & -17.23 & & -17.68 & & -8.8 & \\
\hline \multicolumn{7}{|c|}{ Percentile of BaseDeforestation, (\%) } \\
\hline & 4,356 & 4,356 & 4,356 & 4,356 & 4,356 & 4,356 \\
\hline \multicolumn{7}{|l|}{ Observations } \\
\hline Additional controls & Yes & & Yes & & Yes & \\
\hline Municipality time trend & Yes & & Yes & & Yes & \\
\hline
\end{tabular}

Note. Dependent variables are in logs. Effect at 75 th percentile of BaseDeforestation is computed by multiplying the pre-intervention deforestation for the municipality in the 75th percentile of the pre-intervention deforestation by the coefficient on Post $x$ BaseDeforestation, and dividing the resulting value by the mean of dependent variable. All regressions include municipality and year fixed effects. Additional controls include the annual index of crop prices, and the interactions between Post and municipality size, the average percentage of Bolsa Family beneficiaries, and 2004 GDP. Robust standard errors in brackets are clustered at the micro-region level. Significance: $* \mathrm{p}<0.10 * * \mathrm{p}<0.05, * * * \mathrm{p}<0.01$. 
TABLE 6

\section{EFFECTS OF PPCDAM ON GDP AND AGRICULTURAL ACTIVITY}

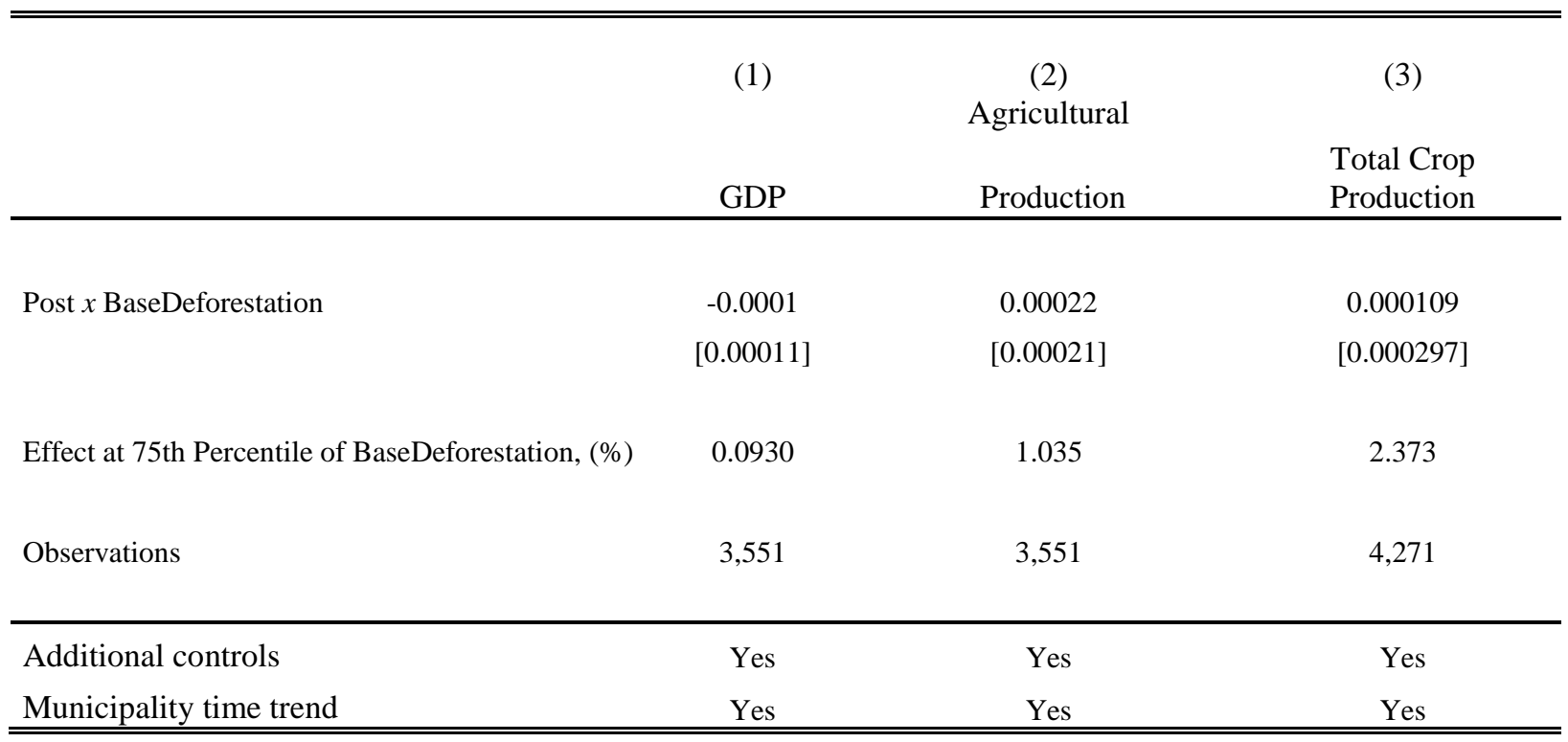

Note. Dependent variables are in logs. Effect at 75th percentile of BaseDeforestation is computed by multiplying the pre-intervention deforestation for the municipality in the 75th percentile of the pre-intervention deforestation by the coefficient on Post $x$ BaseDeforestation, and dividing the resulting value by the mean of dependent variable. All regressions include municipality and year fixed effects. Additional controls include the annual index of crop prices, and the interactions between Post and municipality size, the average percentage of Bolsa Family beneficiaries, and 2004 GDP. Robust standard errors in brackets are clustered at the micro-region level. Significance: $* \mathrm{p}<0.10 * * \mathrm{p}<0.05, * * * \mathrm{p}<0.01$. 


\section{A Appendix}

\section{A1. Air Pollution Data}

We build series for $\mathrm{PM}_{10}, \mathrm{CO}$ y $\mathrm{SO}_{2}$ using data from the Emissions Database for Global Atmospheric Research (EDGAR). This dataset provides worldwide annual estimates for various air pollutants (measures in tonnes) at the $0.1 \times 0.1$ degree latitude/longitude grid $(0.1$ degree correspond roughly to 11 kilometers). Using spatial interpolation methods, EDGAR computes values for each grid node from different emission sources (such as fuel combustion, industrial process, savanna burning, waste burning, forest fires, fossil fuel fires, etc.). We used geospatial software to aggregate the pollutant data to municipality-year level for the period 1998-2008. The mean per municipality per year of levels of $\mathrm{PM}_{10}, \mathrm{CO}$ and $\mathrm{SO}_{2}$ are 4,703 (Standard Deviation=12,560), 39,191 (Standard Deviation=103,200), and 678 (Standard Deviation=1,365), respectively.

\section{A2. Crop Price Index}

In this section, we described the construction of an annual index of crop prices at municipality level. Our procedure follows that of Assunção and Rocha (2015). As these authors, we use crop prices collected in the Agriculture and Supply Secretariat of the State of Paraná (SEABPR) for the period 1998-2008 since crop prices are likely to be endogenous to local productions. Paraná is a state that is not part of the Brazilian Amazon, but the average weighted prices across municipalities in the sample are highly correlated with price from SEAB-PR. The commodities include soybean, cassava, rice, corn and sugarcane. These crops are predominant in the Amazon, representing about $70 \%$ of the total 2004 harvested area.

The index of crop prices is calculated in three stages. First, the nominal annual price of each commodity is deflated and expressed as an index, taking 2000 as base. Second, we calculate the price of each crop for each municipality:

$$
W I P_{i t c}=I P_{t c} x \overline{S C r o p}_{i c}
$$

Where $W I P_{i t c}$ is the real price of the crop $c$ for municipality $i$ and year $t . \mathrm{IP}_{\mathrm{tc}}$ is the price index of crop $c$ in year $t$ built in the first stage. $\overline{s C r o p}_{i c}$ is the average (for the period 1995-1997) 
ratio between the sowed area of crop $c$ and the total sowed area. This term captures the importance of crop $c$ for municipality $i$.

Third, the principal components technique is used to build the annual index of crop prices. We normalize such an index by subtracting the minimum value and dividing the resulting value by the difference between the maximum and minimum values. Thus, the annual index ranges from 0 to 100 . 


\section{A3. Additional tables and figures}

\section{TABLE A1}

EFFECTS OF PPCDAM ON INFANT HEALTH (YEARLY INTERACTION EFFECTS)

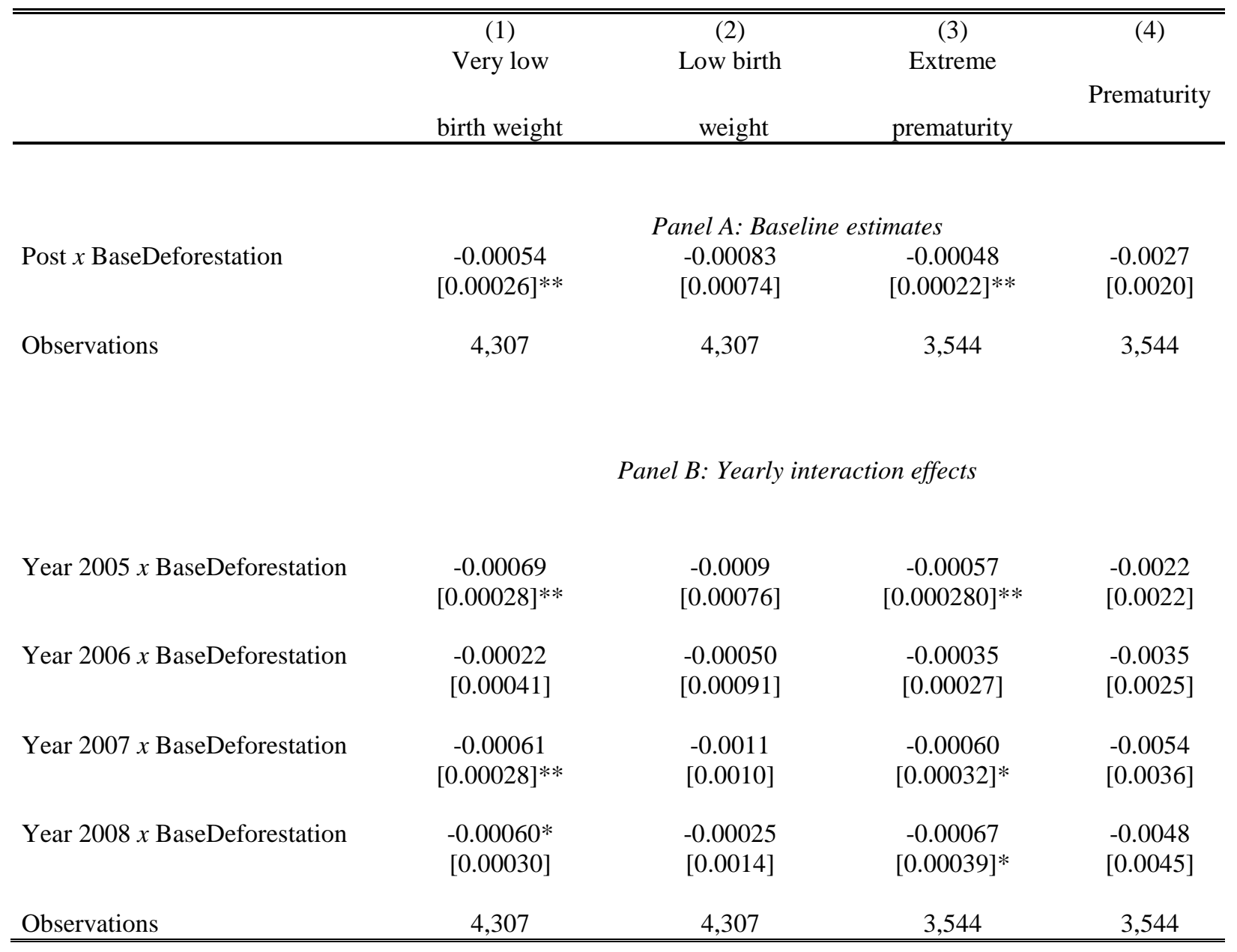

Note. Effect at 75th percentile of BaseDeforestation is computed by multiplying the pre-intervention deforestation for the municipality in the 75th percentile of the pre-intervention deforestation by the coefficient on Post $x$ BaseDeforestation, and dividing the resulting value by the mean of dependent variable. Additional controls include: interactions between Post and the average percentage of Bolsa Family beneficiaries, and 2004 GDP; fixed effects for municipality and year; $\%$ of teenage mother, $\%$ of married mother, and $\%$ of Mother with Education years $>12$. Robust standard errors in brackets are clustered at the micro-region level. Significance: $* \mathrm{p}<0.10 * * \mathrm{p}$ $<0.05, * * * \mathrm{p}<0.01$. 
TABLE A2

EFFECTS OF PPCDAM ON INFANT HEALTH (ALTERNATIVE SPECIFICATIONS)

(1)

(2)

(3)

(4)

(5)

(6)

(7)

Panel A: Dependent variable is Very Low Birth-Weight Rate

Post $x$ BaseDeforestation

Observations

Post $x$ BaseDeforestation

Observations

Post $x$ BaseDeforestation

Observations

Post $x$ BaseDeforestation

Observations

Education and health spending share

Post $x$ Child labor rate

Post $x$ Illiteracy rate

Post $x$ Sanitation coverage

Post $x$ Physicians per capita

Baseline controls

Municipality time trend

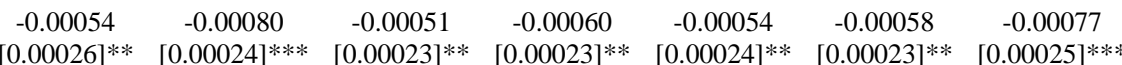

4,307

3,552

4,209

4,209

4,209

4,209

3,462

Panel B: Dependent variable is Low Birth-Weight Rate

$\begin{array}{ccccccc}-0.00083 & -0.0019 & -0.0011 & -0.0010 & -0.00099 & -0.0010 & -0.0023 \\ {[0.0007]} & {[0.0009] * *} & {[0.00076]} & {[0.00073]} & {[0.00077]} & {[0.00077]} & {[0.00108] * *}\end{array}$

$[0.0007] \quad[0.0009]^{* *} \quad[0.00076] \quad[0.00073] \quad[0.00077] \quad[0.00077] \quad[0.00108]^{* *}$

4,307

3,552

4,209

4,209

4,209

4,209

3,462

Panel C: Dependent variable is Extreme Prematurity Rate

Note. Effect at 75th percentile of BaseDeforestation is computed by multiplying the pre-intervention deforestation for the municipality in the 75th percentile of the pre-intervention deforestation by the coefficient on Post $x$ BaseDeforestation, and dividing the resulting value by the mean of dependent variable. Baseline controls include: interactions between Post and the average percentage of Bolsa Family beneficiaries, and 2004 GDP; fixed effects for municipality and year; $\%$ of teenage mother, $\%$ of married mother, and \% of Mother with Education years $>12$. Robust standard errors in brackets are clustered at the micro-region level. Significance: $* \mathrm{p}<0.10 * * \mathrm{p}<0.05$, $* * * \mathrm{p}<0.01$.

\section{TABLE A3}




\section{EFFECTS OF PPCDAM ON INFANT HEALTH (MEAN REVERSION)}

\begin{tabular}{|c|c|c|c|}
\hline & $\begin{array}{c}(1) \\
\text { Baseline } \\
\text { specification } \\
\end{array}$ & $\begin{array}{c}\text { (2) } \\
\text { Lagged } \\
\text { dep. var } \\
\end{array}$ & $\begin{array}{c}\text { (3) } \\
\text { Arellano- } \\
\text { Bond } \\
\end{array}$ \\
\hline & \multicolumn{3}{|c|}{ Panel A: Dependent variable is Very Low Birth-Weight Rate } \\
\hline Post $x$ BaseDeforestation & $\begin{array}{c}-0.00054 \\
{[0.00026]^{* *}}\end{array}$ & $\begin{array}{c}-0.0007 \\
{[0.00026]^{* * *}}\end{array}$ & $\begin{array}{c}-0.0011 \\
{[0.00035]^{* * *}}\end{array}$ \\
\hline One-year lagged Very Low Birth-Weight Rate & & $\begin{array}{c}-0.22 \\
{[0.0203]^{* * *}}\end{array}$ & $\begin{array}{l}-0.029 \\
{[0.026]}\end{array}$ \\
\hline Observations & 4,307 & 3,912 & 3,515 \\
\hline Post $x$ BaseDeforestation & $\begin{array}{c}-0.00083 \\
{[0.00074]}\end{array}$ & $\begin{array}{c}\text { variable is Lo } \\
-0.0014 \\
{[0.00091]}\end{array}$ & $\begin{array}{c}-0.0019 \\
{[0.00099]^{*}}\end{array}$ \\
\hline One-year lagged Low Birth-Weight Rate & & $\begin{array}{c}-0.180 \\
{[0.0327]^{* * *}}\end{array}$ & $\begin{array}{c}-0.0186 \\
{[0.0409]}\end{array}$ \\
\hline Observations & 4,307 & 3,912 & 3,515 \\
\hline & \multicolumn{3}{|c|}{ Panel C: Dependent variable is Extreme Prematurity Rate } \\
\hline Post $x$ BaseDeforestation & $\begin{array}{c}-0.00048 \\
{[0.00022]^{* *}}\end{array}$ & $\begin{array}{c}-0.00041 \\
{[0.00022]^{*}}\end{array}$ & $\begin{array}{c}-0.00052 \\
{[0.00024]^{* *}}\end{array}$ \\
\hline One-year lagged Extreme Prematurity Rate & & $\begin{array}{c}-0.249 \\
{[0.0627]^{* * *}}\end{array}$ & $\begin{array}{c}-0.0749 \\
{[0.0648]}\end{array}$ \\
\hline Observations & \multicolumn{3}{|c|}{ Panel D: Dependent variable is Prematurity Rate } \\
\hline Post $x$ BaseDeforestation & $\begin{array}{c}-0.0027 \\
{[0.0020]}\end{array}$ & $\begin{array}{c}-0.00156 \\
{[0.00175]}\end{array}$ & $\begin{array}{c}-0.000553 \\
{[0.00179]}\end{array}$ \\
\hline One-year lagged Prematurity Rate & & $\begin{array}{c}0.109 \\
{[0.0477]^{* *}}\end{array}$ & $\begin{array}{c}0.221 \\
{[0.0398]^{* * *}}\end{array}$ \\
\hline Observations & 3,544 & 3,148 & 2,752 \\
\hline Baseline controls & Yes & Yes & Yes \\
\hline Municipality time trend & Yes & Yes & Yes \\
\hline
\end{tabular}

Note. Effect at 75th percentile of BaseDeforestation is computed by multiplying the pre-intervention deforestation for the municipality in the 75th percentile of the pre-intervention deforestation by the coefficient on Post $x$ BaseDeforestation, and dividing the resulting value by the mean of dependent variable. Baseline controls include: interactions between Post and the average percentage of Bolsa Family beneficiaries, and 2004 GDP; fixed effects for municipality and year; $\%$ of teenage mother, $\%$ of married mother, and $\%$ of Mother with Education years $>12$. Robust standard errors in brackets are clustered at the micro-region level. Significance: $* \mathrm{p}<0.10 * * \mathrm{p}<0.05$, $* * * \mathrm{p}<0.01$. 
TABLE A4

\section{FALSIFICATION TESTS AND EFFECTS OF PPCDAM ON FETAL DEATH AND SEX RATIO}

\begin{tabular}{|c|c|c|c|c|c|}
\hline & $\begin{array}{l}(1) \\
\text { Fetal }\end{array}$ & $\begin{array}{l}(2) \\
\text { Sex }\end{array}$ & $\begin{array}{c}(3) \\
\% \text { Teenage }\end{array}$ & $\begin{array}{c}(4) \\
\% \text { Mother's }\end{array}$ & $\begin{array}{c}(5) \\
\text { Pregnancy }\end{array}$ \\
\hline & Death Rate & Ratio & Mother & $\begin{array}{c}\text { Education Years } \\
>12 .\end{array}$ & Rate \\
\hline Post $x$ BaseDeforestation & $\begin{array}{l}-0.000645 \\
{[0.000696]}\end{array}$ & $\begin{array}{l}0.0000192 \\
{[0.000068]}\end{array}$ & $\begin{array}{c}-0.0029 \\
{[0.00188]}\end{array}$ & $\begin{array}{c}0.00274 \\
{[0.00348]}\end{array}$ & $\begin{array}{r}-0.000862 \\
{[0.00189]}\end{array}$ \\
\hline Observations & 4,313 & 4,308 & 4,307 & 4,310 & 4,317 \\
\hline Additional controls & Yes & Yes & Yes & Yes & Yes \\
\hline Municipality time trend & Yes & Yes & Yes & Yes & Yes \\
\hline
\end{tabular}

Note. All regressions include municipality and year fixed effects. Additional controls include the annual index of crop prices, and the interactions between Post and municipality size, the average percentage of Bolsa Family beneficiaries, and 2004 GDP. Robust standard errors in brackets are clustered at the micro-region level. In addition, columns (1)-(2) include controls regarding maternal characteristics. $* \mathrm{p}<0.10 * * \mathrm{p}<0.05, * * * \mathrm{p}<0.01$ 
Figure A1. Trends in Mother's Characteristics
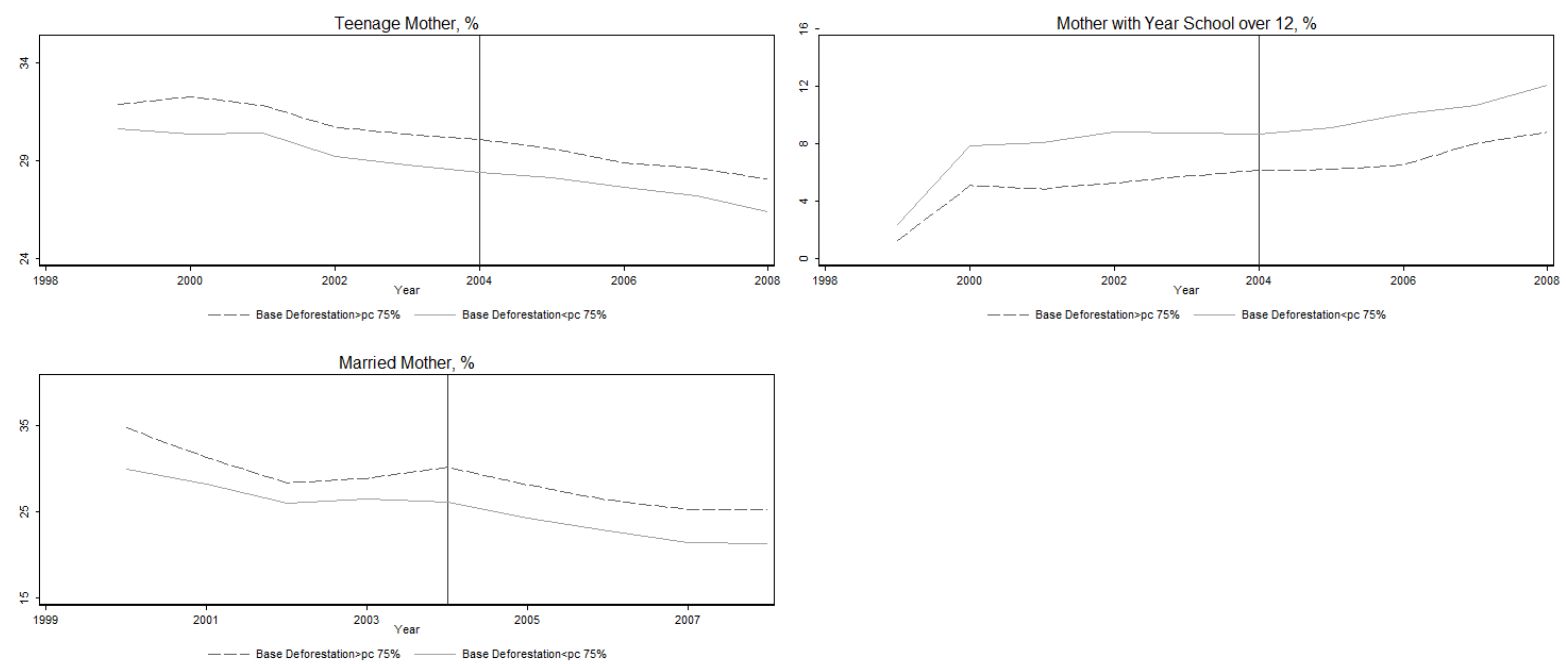

Note. Deforestation is defined as the annual forest cleared in $\mathrm{km} 2$. The municipalities were classified into Low and High categories based on their preintervention deforestation. The Low (High) category consists of municipalities under (over) the 75 percentile of the pre-intervention deforestation.

Figure A2. Difference-in-Difference Coefficient in the Pre-intervention Period
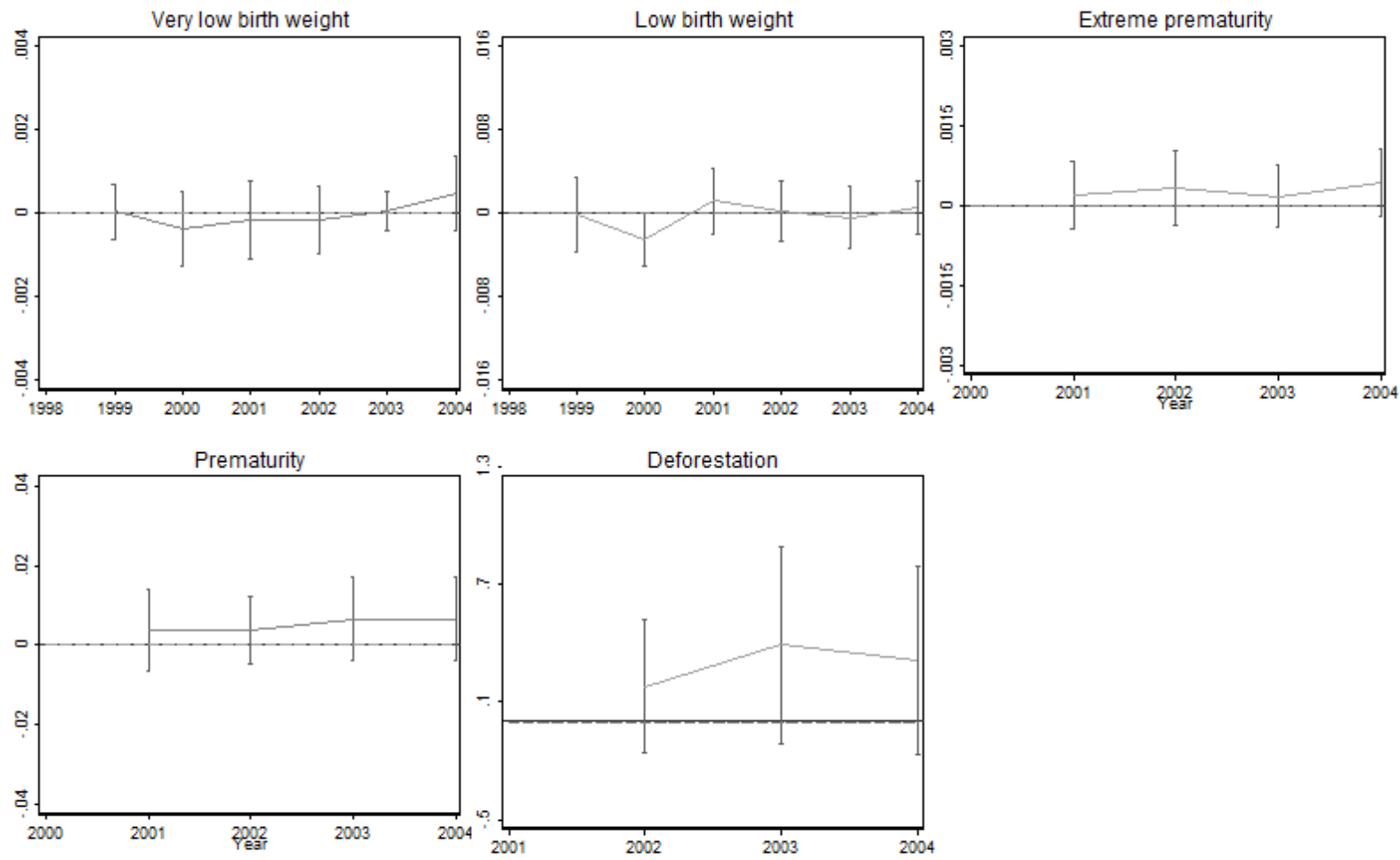

Note. These figures plot coefficients and 95\% confidence intervals from Equation (3). 